\title{
Bienestar Subjetivo y Económico: Análisis Longitudinal para Ecuador*
}

\author{
David Puebla* \\ Director: Leonardo Gasparini
}

\begin{abstract}
Resumen
El presente trabajo analiza la relación entre el bienestar subjetivo y económico, considerando un factor objetivo como el ingreso y subjetivos como la percepción de la pobreza y las aspiraciones económicas. El análisis se efectúa para el caso ecuatoriano entre 2013 y 2014, mediante el uso de información de datos de panel. Al mitigar en el mayor grado posible el sesgo por variables omitidas mediante la inclusión de efectos fijos y otras características variantes en el tiempo, se encontró que el bienestar subjetivo financiero y global no se relacionan de igual forma con los factores analizados. En el primer caso son importantes factores como el ingreso y la percepción absoluta de la pobreza; mientras que en el segundo son importantes las dimensiones de comparabilidad social y aspiraciones económicas. El ingreso no muestra una relación con el bienestar global, al contrario de lo que suele hallarse en estudios que emplean datos de corte transversal.
\end{abstract}

Palabras clave: Bienestar subjetivo, percepción de pobreza, aspiraciones económicas.

Código JEL: I3, D31, D01.

\begin{abstract}
This paper analyzes the relationship between subjective and economic wellbeing, considering an objective factor such as income and subjective factors such as the perception of poverty and economic aspirations. The analysis is performed with panel data from Ecuador for 2013 and 2014. By mitigating as much as possible the omitted variable bias, through the inclusion of fixed effects and other characteristics that change over time, it was found that financial and global wellbeing are not related in the same way to the factors analyzed: income and absolute perception of poverty are important in the first case, while social comparability and economic aspirations are important in the second one. Income does not have a relationship with global well-being, contrary to what is usually found in studies that use cross-sectional data.
\end{abstract}

Keywords: Subjective well-being, perception of poverty, economic aspirations. JEL classification: I3, D31, D01.

\footnotetext{
*El presente trabajo constituye la tesis de Maestría en Economía de la UNLP, realizada bajo la dirección de Leonardo Gasparini. A él agradezco su valiosa guía y apoyo para culminar esta investigación. Los errores son de mi responsabilidad.

${ }^{* *}$ E-mail: david.puebla@hotmail.com
} 


\section{Introducción}

Tradicionalmente, el bienestar y progreso de una sociedad ha sido evaluado en función de indicadores económicos objetivos como el PIB. Esto se debe esencialmente a la premisa de que la utilidad de un individuo viene dada por el grado en que puede satisfacer sus preferencias en el mercado de bienes y servicios (Graham, 2009). Así, su utilidad puede ser maximizada solo cuando se cumplen ciertos requerimientos como la racionalidad y la información completa (Dolan et al., 2008). No obstante, varias de estas premisas han sido cuestionadas (Kahneman, 2011), así como el uso del axioma de preferencias reveladas como indicador de bienestar (Diener y Seligman, 2004; Graham y Pettinato, 2002; Kruger y Engelbrecht, 2010) . Además, a pesar de que los indicadores económicos permiten realizar evaluaciones objetivas del bienestar, no están exentos de desventajas: no consideran externalidades negativas como la contaminación, no contabilizan la producción de actividades no remuneradas y omiten beneficios como el acceso a servicios públicos (Diener y Seligman, 2004; Ravallion, 2014).

La economía de la felicidad, basada en la psicología, ha buscado enfocar el bienestar de un individuo desde una perspectiva distinta. Esta trata de determinar la calidad de vida de las personas a través de su propia evaluación, en función de aspectos y dimensiones que consideran importantes (Graham, 2009). Además, su medición incorpora aspectos no incluidos en los indicadores objetivos, tales como la calidad de vida, calidad de servicios públicos, expectativas, satisfacción de necesidades, logro de metas, etc. (Dang e Ianchovichina, 2016; Diener, 2000). Asimismo, desde un punto de vista político, mantener en la población un sentimiento de satisfacción con la vida contribuye a la sostenibilidad de las democracias y de los procesos políticos (Graham y Pettinato, 2002; Inglehart, 2000).

El bienestar subjetivo es una rama multidisciplinaria, estudiada en campos como la economía, filosofía, psicología y sociología, lo cual implica que su análisis puede enfocarse desde varias perspectivas, que pueden a su vez complementarse. Sin embargo, determinar qué factores inciden sobre el bienestar se vuelve un tema complejo dada la cantidad de dimensiones a tomarse en cuenta. Los factores que pueden afectar el bienestar de una persona se pueden clasificar en internos y externos. Los primeros, analizados

principalmente por psicólogos, pueden estar asociados a la personalidad y temperamento de una persona; los factores externos en cambio provienen del entorno que rodea a la persona y de otras características como el ingreso y el estatus social (Diener, 2009).

Existe una abundante evidencia empírica que ha analizado la relación entre el 
bienestar subjetivo y el nivel de ingresos, a nivel micro y macroeconómico (Easterlin, 1974, 1995; Kahneman y Deaton, 2010; Knight y Gunatilaka, 2012; Stutzer, 2004). Si bien, estos estudios han permitido obtener conclusiones interesantes, la mayoría se ha enfocado en el análisis de asociaciones a través de datos de corte transversal. En general, la asociación entre el bienestar objetivo y subjetivo ha sido positiva; sin embargo, esta relación puede deberse a que existen otras dimensiones que no han sido debidamente controladas y que actúan a la vez sobre la mayor capacidad de obtención de ingresos y el nivel de satisfacción con la vida.

Existen varios estudios que, al poseer una estructura de datos de panel, han logrado controlar, además de las características usuales como el nivel de instrucción, estado civil, la edad, capital social, etc., características invariantes en el tiempo. No obstante, estos han sido realizados mayormente en países de alto desarrollo económico, por la disponibilidad de información con esta estructura de datos (Diener et al., 1993; Hadjar y Samuel, 2015; Li, 2016), aunque existen ciertas excepciones como el trabajo de Graham y Pettinato (2002) desarrollado en Perú y Rusia.

El presente trabajo pretende estudiar cómo el bienestar subjetivo de las personas -medido como la satisfacción financiera y con la vida en general - cambia con el nivel de ingresos y otros factores de percepción. Si bien, una mejora de las condiciones económicas de una persona puede traer consigo varias ventajas como un mayor acceso a la salud, vivienda, educación y otros bienes y servicios, cabe preguntarse si esto es suficiente para que una persona sienta una mejora en su percepción de bienestar. Adicionalmente, se analizan otros aspectos no necesariamente ligados a cuestiones objetivas, como la percepción del estatus socioeconómico y las aspiraciones económicas, y se evalúa si los dos tipos de bienestar analizados se asocian de la misma forma con los factores de interés. También se aporta con evidencia empírica acerca de cómo estas relaciones se dan en un país en vías de desarrollo, ya que inicialmente se podría pensar que, para la gente pobre de estos países, un aumento del ingreso sería suficiente para que el bienestar subjetivo aumente. Finalmente, el trabajo se alinea con otros estudios que han hecho uso de datos de panel para llevar a cabo análisis más robustos, con la particularidad de que estos han sido realizados principalmente en países desarrollados.

La información empleada proviene de un panel de hogares de la Encuesta Nacional de Empleo, Desempleo y Subempleo del Ecuador entre 2013 y 2014. En ambos años se dispone de un módulo sobre autopercepción de los hogares en donde se incluyen mediciones subjetivas acerca de la satisfacción con varios aspectos de la vida, percepción de la pobreza en sentido absoluto y relativo, y el monto mínimo necesario para llegar a fin 
de mes. Además, las variables disponibles permiten controlar por características como la edad, nivel de instrucción, estado civil, condición laboral, entre otras; y la estructura de panel permite controlar las características invariantes en el tiempo observables como el género o etnia, e inobservables como la personalidad y habilidades innatas. Con esto se logró mitigar considerablemente el sesgo por variables omitidas, permitiendo obtener conclusiones no necesariamente similares a las halladas en los estudios de corte transversal.

Previo al análisis principal y aprovechando la estructura de datos de panel, mediante un análisis de eventos se pudo determinar cómo cambia el bienestar financiero y global de los hogares, cuando experimentan cambios en el ingreso y condición laboral. Con ello se encontró que, si bien, la asociación entre el bienestar global y el ingreso es positiva en un punto de tiempo, las variaciones del bienestar global entre un periodo y otro no están atadas a cambios del ingreso, lo cual es un indicio de que el bienestar global está afectado por aspectos más allá de los económicos. A diferencia de esto, se pudo notar que los cambios en el bienestar financiero sí se encuentran relacionados con cambios en la situación económica.

Los resultados de los modelos del bienestar financiero y global muestran que su relación con los factores analizados no es similar, a excepción de la comparabilidad social, la cual afecta negativamente a ambos tipos de bienestar. En cuanto al resto de factores, para el bienestar financiero son importantes los recursos económicos con los que cuenta el hogar y de cuán rico o pobre percibe ser; en el caso del bienestar global, son importantes las aspiraciones económicas mínimas.

Cuando se realizó el análisis para distintos tramos de la distribución del ingreso, se pudo notar que la única relación que se mantiene a lo largo de la distribución en ambos tipos de bienestar, tiene que ver con la percepción económica relativa. Es decir, para que una persona posea un mayor nivel de bienestar financiero o global, es más importante que sienta estar en un estatus económico mejor que el grupo de referencia con el cual se está comparando, en lugar de la obtención de un mayor nivel de ingresos. Finalmente, se pudo determinar que la relación negativa entre el bienestar global y las aspiraciones económicas, se da únicamente en los tres quintiles menores de ingreso, que son los que presentan la mayor brecha entre el ingreso y las aspiraciones económicas mínimas. Al analizar posibles mecanismos, se encontró que estos hogares poseen una menor satisfacción con respecto a la participación en la comunidad, vida social, familia y tiempo libre. Por lo tanto, se trataría de personas que destinan su tiempo a un trabajo poco remunerado que les impide contar con tiempo libre para realizar actividades que 
aportan positivamente al bienestar, como la interacción social o pasar tiempo con la familia.

El resto del trabajo se estructura de la siguiente manera: en la sección 2 se realiza una revisión de la literatura sobre la conceptualización del bienestar subjetivo y las características que lo afectan; en la sección 3 se expone la fuente de datos empleada y la estrategia metodológica a seguir; en la sección 4 se describen los resultados hallados, y; finalmente, en la sección 5 se resumen las principales conclusiones.

\section{Aspectos teóricos}

\subsection{Bienestar subjetivo}

El bienestar subjetivo puede definirse de varias formas. Según Graham (2009), el bienestar hace referencia a una evaluación propia de la calidad de vida de las personas en función de aspectos y dimensiones que consideran importantes. Para Diener (2009), el bienestar surge cuando una persona cree que su vida es deseable, placentera y buena; mientras que para Shin y Johnson (1978), el bienestar puede entenderse como una evaluación global de las situaciones de la vida, y de la comparación de estas situaciones frente a las del resto y con respecto a su pasado.

El bienestar subjetivo ha sido analizado bajo dos enfoques: cognitivo y afectivo. En el primer caso, el individuo evalúa su bienestar en base al grado de satisfacción con varios dominios de la vida como la salud, finanzas, seguridad, capital social, etc. (Diener et al., 2002). En el segundo caso, los individuos evalúan su bienestar en función de lo que consideran relevante, y de las experiencias que viven en el día a día, incluyendo episodios de diversión, estrés, tristeza, angustia, etc. (Diener, 2009). Sin embargo, es importante considerar que los factores que inciden en ambos enfoques del bienestar no necesariamente son los mismos (Kahneman y Deaton, 2010).

\subsection{Factores que inciden en el bienestar subjetivo}

El bienestar subjetivo ha sido estudiado en diversas disciplinas como la economía, filosofía, psicología y sociología; sin embargo, los estudios han sido desarrollados en el marco de las propias disciplinas (Diener, 2009). Esto por una parte abre la posibilidad de sacar el máximo provecho de los avances de cada disciplina para complementarlas y poder llevar a cabo un análisis más amplio; pero por otra parte, dada la cantidad de 
dimensiones a tomarse en cuenta, el análisis no necesariamente puede resultar sencillo.

Los factores que pueden afectar el bienestar de una persona se pueden clasificar en internos y externos. Los primeros, analizados principalmente por psicólogos, pueden estar asociados a la personalidad y temperamento de una persona. Los factores externos en cambio provienen del entorno que rodea al individuo como el grado de inseguridad, ambiente político, contaminación, etc.; y de otras características como el ingreso, estatus social, etc. (Diener, 2009).

El factor externo más estudiado es el nivel de ingresos de una persona (Clark et al., 2008; Diener y Biswas-Diener, 2002). La evidencia muestra que, en general, la relación entre el ingreso y el bienestar social ocurre en mayor grado en países y zonas pobres que no han podido satisfacer sus necesidades básicas, argumento que justificaría el uso de indicadores económicos objetivos como proxies del bienestar social (Ravallion y Lokshin, 2010; Tov y Diener, 2009). No obstante, en países que han logrado alcanzar un nivel de desarrollo económico importante, una mejora en el ingreso no necesariamente se asocia con un aumento del bienestar (Cummins, 2000; Easterlin, 1974, 1995; Kahneman y Deaton, 2010). A pesar de ello, al interior de los países se suele encontrar una asociación positiva entre los ingresos y el bienestar, independientemente del nivel de desarrollo. Este fenómeno, conocido como la paradoja de Easterlin, sugiere que las políticas enfocadas a incrementar el bienestar económico pueden resultar viables hasta cierto punto, ya que hay otros aspectos no necesariamente ligados a logros materiales y objetivos que van tomando importancia (Diener, 2009; Putman, 2000; Tov y Diener, 2009; Wilkinson y Pickett, 2009).

Otros factores que pueden afectar al bienestar son características como la edad, género, etnia, estado civil, salud, empleo, educación, religión, contacto social, personalidad, uso de tiempo, entorno económico y político, etc. (Clark et al., 2008; Diener, 2009; Dolan et al., 2008; Graham, 2009; Graham y Pettinato, 2002). De estas variables, la evidencia sobre las características demográficas es amplia y mixta, predominando asociaciones estadísticamente significativas aunque con un poder explicativo bajo (Diener, 1984; Diener et al., 1999).

Por su parte, el poder predictivo de variables como la personalidad -autoestima, optimismo, confianza, etc.- y el capital social resultan ser importantes (Lucas y Diener, 2008; Putman, 2000). Finalmente, las variables de entorno económico (e.g. desigualdad, desempleo o inflación) y político (e.g. ausencia de democracia), inciden negativamente sobre el bienestar de las personas, a través de mecanismos como la incertidumbre sobre su futuro próximo y de sentimientos de frustración (Alem y Colmer, 2015; Alesina et al., 
2004; Di Tella et al., 2001; Wolfers, 2003).

\subsection{Bienestar subjetivo y factores adicionales a los indicadores objetivos}

Si bien, la evidencia que estudia la relación entre el bienestar subjetivo y económico de una sociedad es amplia, estas mayormente han sido realizadas en un sentido estático, es decir, analizando puntos de tiempo específicos y su evolución a lo largo del tiempo. Sin embargo, dada la creciente disponibilidad de datos de panel, principalmente en países desarrollados, la evidencia sobre cómo la movilidad económica puede incidir en el bienestar de las personas, así como los mecanismos que estarían detrás, ha crecido considerablemente (Graham y Pettinato, 2002; Hadjar y Samuel, 2015; Li, 2016; Molnar y Kapitány, 2006; Nikolaev y Burns, 2014; Zang y de Graaf, 2016).

En general se ha encontrado que la relación entre el bienestar económico, medido mediante cualquier indicador económico usual, y subjetivo de una sociedad, no es simple: la mejora del bienestar económico no evoluciona a la par del bienestar subjetivo ya que puede abarcar varios mecanismos a la vez. En este sentido, han sido varias las teorías propuestas y estudiadas para explicar los fenómenos que pueden intervenir en la relación bienestar-ingresos, de las cuales a continuación se exponen las de mayor sustento teórico y empírico. Adicionalmente, cabe recalcar que las teorías presentadas no son excluyentes entre sí.

\subsubsection{Comparación social o privación relativa}

Bajo la premisa de la comparación social, una persona es feliz cuando percibe que está en un mejor estatus social o económico que otros, ya que esto le genera un sentimiento de prestigio, valor y aprobación (Anderson et al., 2012; Hirsch, 1976; Liang et al., 1980). La comparación relativa se puede dar, aunque en diferente grado, en sociedades de alto y bajo desarrollo económico, lo cual permite sustentar de cierto modo la paradoja de Easterlin (Brockmann et al., 2008; Corazzini et al., 2011; Graham y Pettinato, 2002; Molnar y Kapitány, 2006; Zang y de Graaf, 2016). Además, esto permite explicar por qué, a pesar de que aumenten los estándares económicos de una sociedad, puede existir un sentimiento de frustración cuando la desigualdad es creciente, dado que los beneficiados pueden ser pocos y los rezagados sentirían estar en un estatus inferior al de ellos (Cancho et al., 2015). 
Un factor importante en la teoría de la comparación relativa es el punto de referencia que un individuo toma para compararse. Los entornos de referencia más estudiados han sido los espacios geográficos y grupos cercanos como amigos, familia y compañeros de trabajo. En este último caso, se ha encontrado evidencia de que la satisfacción con el trabajo depende en gran medida del pago que recibe un trabajador en comparación con el de otros, y más no del nivel salarial absoluto (Clark y Oswald, 1996).

\subsubsection{Hipótesis disociativa}

Cuando una persona adquiere un mayor nivel de ingresos o riqueza, su estilo de vida puede cambiar de distintas formas: mudarse a un nuevo vecindario, suscribirse en clubes con gente de su nuevo estrato, establecer relaciones sociales con un nuevo círculo social, etc. (Houle y Martin, 2011; Putman, 2000).

En este sentido, si bien, mejorar el estatus económico y social puede proporcionar cierta satisfacción personal, esto también puede afectar al bienestar, debido al nuevo entorno en el que debe convivir. Esto ya que, por una parte, el hecho de migrar a un nuevo círculo social puede implicar una pérdida de contacto con la gente de su origen; y por otra parte, la generación de nuevos lazos de amistad no se da de forma automática, sino que implica un proceso de aceptación de los nuevos compañeros. De este modo, si el proceso de socialización falla, el bienestar de la persona puede verse afectado al sentirse socialmente excluido, ya que perdería a los amigos de su clase de origen y no lograría ser aceptado en el nuevo entorno (Hadjar y Samuel, 2015; Li, 2016; Li et al., 2003).

\subsubsection{Adaptación}

Esta teoría, denominada también "caminadora hedónica" (Brickman y Campbell, 1971), establece un mecanismo de adaptación a las nuevas circunstancias. Es decir, cuando una persona vive un evento, sea este durable o no, su impacto sobre el bienestar puede ser transitorio. No obstante, dependiendo del evento, el desvanecimiento puede no darse en un sentido total, sino parcial, lo cual implica un predominio de los efectos de las circunstancias sobre el mecanismo de adaptación (Gasparini, 2010; Suh et al., 1996).

El mecanismo de adaptación aplicado a la movilidad económica implica que si una persona logra contar con un mayor nivel de ingresos, la satisfacción que se derive de esto va a ser temporal. Luego de un tiempo, la persona se acostumbrará al nuevo estilo de vida y su bienestar volverá a los niveles presentados inicialmente. Esta teoría también suele citarse para explicar la paradoja de Easterlin, ya que el hecho de que el 
bienestar no siga aumentando con los ingresos a partir de cierto umbral, significaría que los ingresos solo son importantes hasta cierto punto y que un aumento adicional solo generaría aumentos transitorios en el bienestar.

\subsubsection{Aspiraciones}

El bienestar de una persona puede verse afectado por la brecha entre lo que aspira y lo que en realidad posee. Esto implica que a pesar de que una persona vea aumentar su nivel de vida en un sentido objetivo, el hecho de que sus aspiraciones aumenten en un grado mayor, puede deteriorar su grado de bienestar (Diener y Biswas-Diener, 2002; Knight y Gunatilaka, 2012; Stutzer, 2004).

Este mecanismo está ligado a la adaptabilidad y comparación social, ya que el nivel de aspiraciones va a depender de un punto de referencia que puede variar por deseos propios del individuo o por cuestiones que observa en su entorno. Esto por lo tanto permitiría también explicar la paradoja de Easterlin, ya que el hecho de que un aumento del ingreso no genere un aumento del bienestar puede deberse a que las expectativas económicas aumentan a la par.

\section{Estrategia metodológica}

\subsection{Datos}

La fuente de datos empleada en el presente trabajo es la Encuesta Nacional de Empleo, Desempleo y Subempleo (ENEMDU) del Instituto Nacional de Estadística y Censos (INEC) del Ecuador. Esta encuesta tiene como objetivo monitorear la situación del mercado laboral ecuatoriano y caracterizar varios fenómenos como la pobreza y desigualdad por ingresos. La encuesta se levanta con una frecuencia trimestral y posee una cobertura nacional en los meses de junio y diciembre, y urbana en marzo y septiembre.

La información adicional que recaba la ENEMDU permite caracterizar a la población ecuatoriana en función de aspectos demográficos como el género, edad, autoidentificación étnica, estado civil, nivel de instrucción, etc. Además, con cierta periodicidad se incluyen módulos que indagan temas como la autopercepción de los hogares, inseguridad ciudadana, calidad de servicios públicos, uso de tiempo, etc.

Otra particularidad de la ENEMDU es su esquema de panel rotativo 2-2-2, lo que significa que un hogar es encuestado durante dos trimestres seguidos, se descarta tempo- 
ralmente en los siguientes dos trimestres, y se incluye nuevamente para ser encuestado por dos trimestres más; posterior a esto, el hogar sale definitivamente de la muestra ${ }^{1}$. Por lo tanto, este esquema permite obtener información para un hogar en el mismo mes de distintos años, con lo cual se descartan posibles efectos estacionales que pueden incidir en el fenómeno estudiado.

En este estudio se considera el panel correspondiente a los meses de diciembre de 2013 y 2014, debido a que cuentan con el módulo de autopercepción de los hogares. Este incluye preguntas que miden la satisfacción con varios aspectos de la vida (e.g. situación financiera, estado de salud, vida social, etc.) y la vida en general, percepción de la pobreza en sentido absoluto y relativo, y el monto mínimo necesario para que un hogar llegue a fin de mes. En concreto, las variables de interés y sus respectivas preguntas son las siguientes:

I Satisfacción general con la vida:

En una escala de 1 a 10 donde 1 significa totalmente infeliz y 10 significa totalmente feliz ¿Cómo se siente usted con respecto a la satisfacción general tomando en cuenta todos los aspectos de su vida?

II Satisfacción financiera:

En una escala de 1 a 10 donde 1 significa totalmente infeliz y 10 significa totalmente feliz ¿Cómo se siente usted con respecto a su situación financiera?

III Percepción de estatus socioeconómico desde un punto de vista absoluto, es decir, sin compararse con nadie:

¿Usted considera que su hogar es pobre? ¿sí o no?

IV Percepción de estatus socioeconómico desde un punto de vista relativo, es decir, comparándose con el resto:

Imagine una escalera con diez escalones/gradas, donde en el primer escalón, están las personas más pobres y en el último escalón, están los más ricos ¿en cuál escalón se ubicaría usted hoy $?^{2}$

V Aspiraciones (Ingreso mínimo para vivir bien):

\footnotetext{
${ }^{1}$ El esquema de panel rotativo 2-2-2 permite contar con un panel de hogares en el mismo mes de dos años seguidos con un tamaño muestral equivalente al $50 \%$ del total. No obstante, para efectos de análisis, el INEC reajusta los factores de expansión para que esta muestra represente al total de la población.

${ }^{2}$ En las regresiones se invierte el sentido para que tenga el mismo signo que la percepción absoluta de estatus socioeconómico.
} 
En su opinión ¿cuáles son los ingresos mensuales netos que como mínimo se necesitarían para que un hogar como el suyo llegue a fin de mes?

\subsection{Metodología}

La sección de resultados (sección 4) se divide en cuatro partes. En la primera se exponen características generales de la población de estudio y la evolución de los ingresos de los hogares que conforman el panel.

En la segunda parte se analiza la relación entre las cinco variables de interés del módulo de autopercepción de los hogares y el ingreso. Con esto se pretende dar un panorama similar al que estamos acostumbrados con los estudios de corte transversal, en los cuales suelen predominar las asociaciones positivas entre el ingreso y las variables económicas.

En esta misma sección, cuando se analiza la proxy de aspiraciones, se realiza un análisis de cómo varía el nivel de aspiraciones cuando varía el ingreso. Con ello se pretende determinar si en el contexto de estudio las aspiraciones económicas son crecientes a medida que aumenta el ingreso y su magnitud. Adicionalmente, se pretende determinar si las aspiraciones económicas que reportan los hogares dependen solamente de factores objetivos, lo cual es esperable si se considera que la pregunta indaga sobre un valor mínimo necesario.

El modelo que se estima para este propósito es el siguiente:

$$
A s p_{i t}=\beta_{0}+\beta_{1} Y_{i t}+\beta_{2} P_{-} A b s_{i t}+\beta_{3} P_{-} \operatorname{Re}_{i t}+\beta_{4} X_{i t}+\gamma_{i}+\eta_{t}+\epsilon_{i t}
$$

Donde:

- Asp $p_{i t}$ : Aspiraciones (logaritmo).

- $Y_{i t}$ : Ingreso per cápita del hogar (logaritmo).

- $P_{-} A b s_{i t}$ : Percepción absoluta de pobreza.

- $P_{-} R_{e} l_{i t}$ : Percepción relativa de pobreza.

- $X_{i t}$ : Vector de variables que varían en el tiempo: condición de actividad, nivel de instrucción, estado civil y edad.

- $\gamma_{i}$ : Heterogeneidad invariante en el tiempo.

- $\eta_{t}$ : Dummies de año.

- $\epsilon_{i t}$ : Término de error.

Esta estrategia es similar a la que se sigue en los estudios de Stutzer (2004) y 
Knight y Gunatilaka (2012), con la salvedad de que para descartar el problema de endogeneidad entre las aspiraciones y el nivel de ingresos, los autores siguen un enfoque de variables instrumentales ${ }^{3}$. Sin embargo, la limitación de emplear esta estrategia es la dificultad de cumplir con el supuesto de exogeneidad cuando la variable de interés es el bienestar subjetivo, debido a la multiplicidad de aspectos que pueden influir sobre este. A diferencia de ambos trabajos, en el presente estudio se tiene la posibilidad de, además de incluir variables de control que varían en el tiempo, eliminar el sesgo por variables omitidas invariantes en el tiempo mediante la inclusión de efectos fijos.

Una vez que se obtiene un primer panorama sobre la relación entre el ingreso y los factores analizados, el siguiente ejercicio consiste en realizar un estudio de eventos, aunque con la limitación de disponer de un panel de longitud temporal de un año. La idea en este caso es ir más allá de los análisis de corte transversal, en donde usualmente se encuentra una relación positiva entre la condición económica y el bienestar, y analizar si de un periodo a otro, un cambio de condición económica se asocia con un cambio en ambos tipos de bienestar.

En la cuarta parte se presenta la estimación del modelo principal, en el cual se evalúa cómo se asocia el bienestar subjetivo de los hogares con el ingreso, las percepciones sobre el nivel de pobreza y el nivel de aspiraciones. El mismo modelo es utilizado para analizar el bienestar global y financiero, con el fin de determinar si los factores analizados influyen del mismo modo en ambos casos.

Dado que se dispone de una estructura de panel, es posible controlar por las características invariantes en el tiempo a través de un modelo de efectos fijos. Esta estrategia, sumada a la posibilidad de controlar por otras características variantes en el tiempo que influyen sobre el bienestar, permite mitigar, aunque parcialmente, el sesgo por variables omitidas en las relaciones analizadas.

Principalmente, las características invariantes en el tiempo que pueden intervenir en la relación entre el bienestar subjetivo y los factores analizados, y que difícilmente pueden ser medidas con exactitud, tienen que ver con la personalidad y las habilidades de las personas. Las características intrínsecas de las personas como la autoestima, hiperactividad, empatía, autosuficiencia, optimismo, etc., además de influir positivamente sobre el bienestar de una manera directa, también pueden incidir en su motivación para culminar estudios superiores, lograr metas profesionales, habilidad para formar redes de trabajo, etc., facilitando así el acceso a una fuente de ingresos adecuada.

\footnotetext{
${ }^{3}$ Entre las variables instrumentales usadas en estos trabajos se tiene: educación de los padres, activos productivos, composición del hogar por edad y género, entre otras.
} 
El modelo a estimarse es del siguiente tipo:

$$
W_{i t}=\beta_{0}+\beta_{1} Y_{i t}+\beta_{2} P_{-} A b s_{i t}+\beta_{3} P_{-} R_{e} l_{i t}+\beta_{4} A s p_{i t}+\beta_{5} X_{i t}+\gamma_{i}+\eta_{t}+\epsilon_{i t}
$$

Donde:

- $W_{i t}$ : Medida de bienestar subjetivo global o financiero.

- $Y_{i t}$ : Ingreso per cápita del hogar (logaritmo).

- P_Absit : Percepción absoluta de pobreza.

- $P_{-} R_{e} l_{i t}$ : Percepción relativa de pobreza.

- Asp $p_{i t}$ : Aspiraciones (logaritmo).

- $X_{i t}$ : Vector de variables que varían en el tiempo: condición de actividad, nivel de instrucción, estado civil, edad, percepción de la democracia, seguridad, confianza en las instituciones públicas y práctica de deporte.

- $\gamma_{i}$ : Heterogeneidad invariante en el tiempo.

- $\eta_{t}:$ Dummies de año.

- $\epsilon_{i t}$ : Término de error.

De este modo, los parámetros de interés son $\beta_{1}, \beta_{2}, \beta_{3}$ y $\beta_{4}$, aunque también se constata si el sentido del resto de coeficientes guarda consistencia con lo hallado en la literatura.

\section{Resultados}

\subsection{Descripción general}

En la Tabla A.1 se muestran varias características de los jefes de hogar que conforman el panel de hogares 2013-2014. Se puede destacar que los jefes de hogar poseen una edad promedio de aproximadamente 53 años, un 70\% pertenece al género masculino, el $67 \%$ está casado o unido, el $85 \%$ se autoidentifica como mestizos y el $49 \%$ posee instrucción primaria. En cuanto a la condición laboral, se puede resaltar la baja tasa de desempleo que los jefes de hogar experimentaron en ambos años (1,3\%), así como la elevada tasa de empleo no adecuado o subempleo (promedio de $40 \%$ ) $^{4}$. No obstante, con

${ }^{4} \mathrm{El}$ INEC utiliza un nuevo marco conceptual para la población ocupada desde el año 2015 (Castillo, 2015). En este marco se clasifica a las personas ocupadas en empleo adecuado, subempleo, otro empleo no pleno, empleo no remunerado y no clasificado. En el presente trabajo se realiza una agrupación de estas categorías en dos: adecuado y no adecuado, siendo esta última la que agrupa los últimos cuatro tipos de empleo. A continuación se exponen las definiciones empleadas por el (INEC, 2017): i) Empleo adecuado o pleno: Personas con empleo que, durante la semana de referencia, perciben 
respecto a esto último, se puede destacar la caída de 3,5 puntos porcentuales entre 2013 y 2014, lo cual se vio compensado con el aumento de 4 puntos porcentuales del empleo adecuado.

En la Figura 1 se puede notar que en términos reales, el ingreso per cápita promedio de los hogares aumentó entre 2013 y 2014 (desplazamiento hacia la derecha), y que la dispersión disminuyó (menor ensanchamiento y mayor altura). Esto se corrobora también con los estadísticos presentados en la Tabla A.2, en donde se nota un aumento del ingreso per cápita promedio y de cada percentil considerado. En cuanto a la participación de cada decil sobre el total de ingresos, no hay un patrón claro sobre una redistribución en términos relativos; sin embargo, se observa una disminución de la dispersión de los ingresos según el coeficiente de variación y el índice de Gini.

Figura 1: Densidad del logaritmo del ingreso 2013 y 2014.

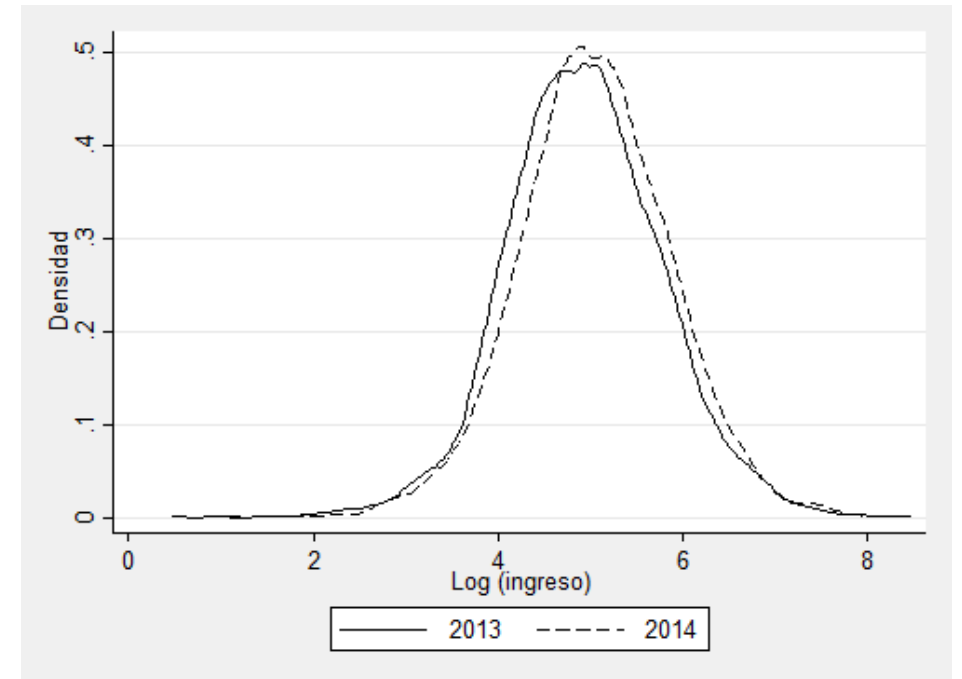

Nota: Ambas distribuciones se expresan en dólares de 2013. Se pondera por factores de expansión.

Fuente: ENEMDU - Diciembre 2003-2014.

ingresos laborales iguales o superiores al salario mínimo, trabajan igual o más de 40 horas a la semana, independientemente del deseo y disponibilidad de trabajar horas adicionales; y personas con empleo que, durante la semana de referencia, perciben ingresos laborales iguales o superiores al salario mínimo, trabajan menos de 40 horas, pero no desean trabajar horas adicionales. ii) Subempleo: Personas con empleo que, durante la semana de referencia, percibieron ingresos inferiores al salario mínimo y/o trabajaron menos de la jornada legal y tienen el deseo y disponibilidad de trabajar horas adicionales. iii) Otro empleo no pleno: Personas con empleo que, durante la semana de referencia, percibieron ingresos inferiores al salario mínimo y/o trabajaron menos de la jornada legal y no tienen el deseo y disponibilidad de trabajar horas adicionales. iv) Empleo no remunerado: Personas con empleo que, durante la semana de referencia, no perciben ingresos laborales. En esta categoría están los trabajadores no remunerados del hogar, trabajadores no remunerados en otro hogar y ayudantes no remunerados de asalariados/jornaleros. v) Empleo no clasificado: Personas empleadas que no se pueden clasificar como empleados adecuados, subempleados, no remunerados, otro empleo no pleno por falta de información en los factores determinantes. Se construye como residuo del resto de categorías. 
Los estadísticos del ingreso per cápita del hogar presentados hasta acá han sido de naturaleza anónima, es decir, considerando a todos los hogares de cada periodo en conjunto sin realizar un seguimiento de las características para un mismo conjunto de hogares. A diferencia de ello, en la Tabla A.3 se muestra cómo se han movilizado los hogares entre 2013 y 2014 a lo largo de la distribución del ingreso a través de una matriz de transición. En específico, cada fila muestra la probabilidad de que un hogar que se ubicó en un determinado quintil en el 2013, se movilice a otro quintil o permanezca en el mismo en el 2014. En la tabla se puede notar que, en general, las probabilidades de permanecer en el mismo quintil entre un año y otro son mayores a las probabilidades de movilidad. Los casos más llamativos se dan en los quintiles extremos: la probabilidad de que un hogar que se encontraba en el quintil más pobre en 2013 permanezca igual en 2014 es de 51,3\%, mientras que en el quintil más rico, la probabilidad de permanencia es de $63,4 \%$. Otro hecho consistente es que la probabilidad de movilidad de un quintil a otro va disminuyendo a medida que se considera un quintil más lejano al del año inicial.

\subsection{Análisis de las variables de interés}

En esta subsección se analiza cómo se relacionan las variables de autopercepción de los hogares (bienestar subjetivo, percepción absoluta y relativa de pobreza y aspiraciones), con el nivel de ingresos. En específico, se divide a la distribución del ingreso del año $2014^{5}$ en deciles, y se analiza cómo se comportan las variables de autopercepción en cada uno. El objetivo es dar un panorama general sobre las asociaciones que surgen en un análisis no condicional.

\subsubsection{Bienestar subjetivo}

En la fuente de datos empleada se pide al informante realizar una evaluación sobre su satisfacción ${ }^{6}$ con respecto a 14 dimensiones: profesión, trabajo, situación financiera, estado de salud, vivienda, tiempo libre, familia, educación, medio ambiente, vida social, estado civil, participación en la comunidad, gobierno y satisfacción general tomando en cuenta todos los aspectos de la vida. De estas dimensiones, las que se analizan en el presente trabajo son la satisfacción con la situación financiera y con la vida en

\footnotetext{
${ }^{5} \mathrm{Al}$ replicar los mismos ejercicios en el año 2013, las conclusiones se mantienen en todos los casos.

${ }^{6}$ Originalmente, la evaluación se mide con una escala discreta de 0 a 10 , donde 0 significa totalmente infeliz y 10 significa totalmente feliz. En el trabajo se unen las calificaciones de 0 y 1 con el fin de facilitar la exposición gráfica al tener un número de categorías par. En términos prácticos, solamente el 0,04\% y $0,06 \%$ en 2013 y 2014, respectivamente, responde estar totalmente infeliz.
} 
general, las cuales son tratadas también como bienestar financiero y bienestar global, respectivamente.

Con respecto al bienestar global, al pedirle al informante que lo evalúe tomando en cuenta todos los aspectos de la vida, su respuesta va a estar influenciada por las dimensiones anteriores. De este modo, el bienestar subjetivo que se mide sigue un enfoque cognitivo, ya que el instrumento de medición establece a priori una serie de dimensiones que van a influir sobre la evaluación de la vida en general, mitigando además el problema de las respuestas afectivas que pueden surgir por el estado de ánimo del individuo.

En la Figura 2 se puede observar que las evaluaciones sobre el bienestar financiero y global se asocian positivamente con el ingreso. Esto debido a que a medida que se considera un decil cada vez mayor, el porcentaje de hogares con evaluaciones de bienestar altas va aumentando. No obstante, este patrón es menos claro en el bienestar global, lo cual da un indicio de que la evaluación del bienestar general estaría afectada por aspectos más allá del nivel de ingresos. A pesar de ello, la asociación no condicionada entre el bienestar subjetivo global y el logaritmo de los ingresos es positiva y estadísticamente significativa con un coeficiente de 0,264, siendo casi un tercio de la asociación hallada entre el bienestar financiero y el logaritmo del ingreso que fue de 0,838. En el resto de dimensiones también se observa una asociación positiva y estadísticamente significativa con el ingreso, aunque las magnitudes mayores se dan en educación $(0,718)$, profesión $(0,680)$, trabajo $(0,647)$ y vivienda $(0,602)^{7}$. A pesar de que estas relaciones son endógenas, es consistente que un mayor logro económico esté asociado mayormente con la satisfacción en cuanto a logros académicos, profesionales, y dimensiones materiales.

Si bien en la sección 4.4 se analiza en mayor detalle la asociación entre el bienestar subjetivo y el nivel de ingresos controlando por otras características, inicialmente se puede destacar que, al igual que en otros estudios de corte transversal, en el caso ecuatoriano hay una relación positiva entre el bienestar subjetivo financiero y global con el ingreso.

\subsubsection{Percepciones del nivel de pobreza}

El cuestionario empleado posee dos preguntas relacionadas a la percepción del nivel de pobreza. En el primer caso se realiza una pregunta cerrada con la finalidad de determinar si el hogar se considera pobre o no. Al no especificar nada adicional en la

\footnotetext{
${ }^{7}$ Las estimaciones se muestran en la Tabla A.4.
} 
Figura 2: Satisfacción financiera y global según deciles de ingreso.
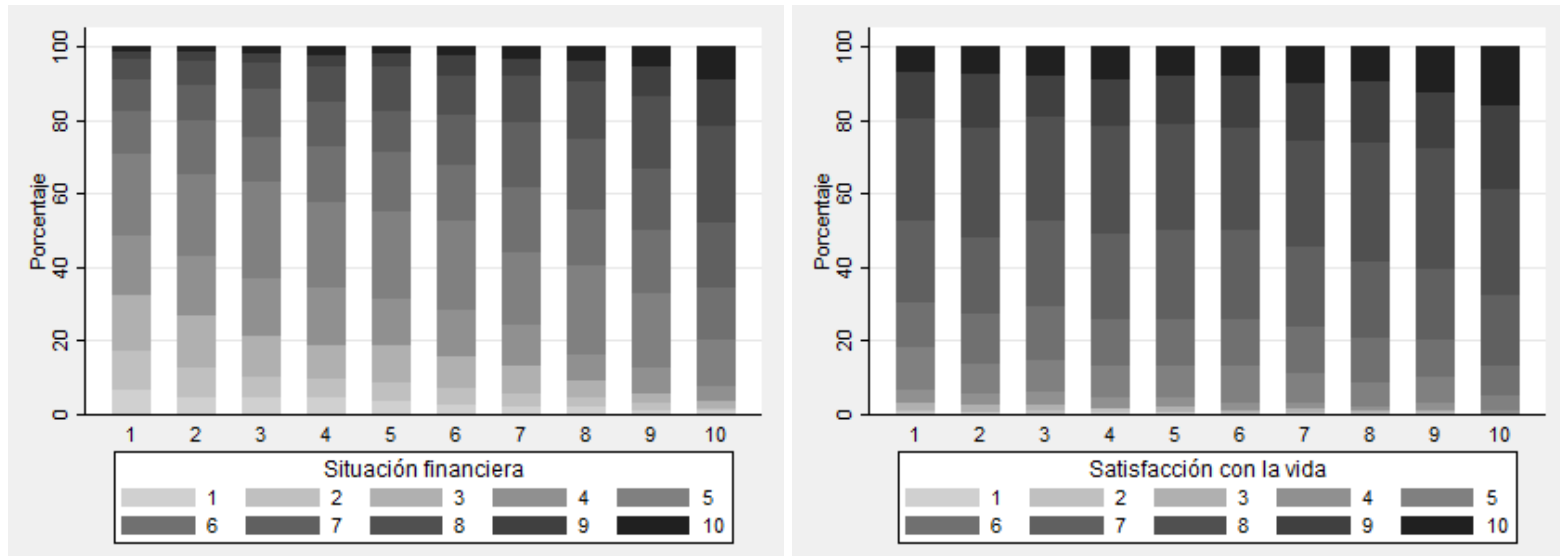

Nota: El eje de las abscisas representa los deciles del ingreso per cápita familiar. Las evaluaciones de satisfacción se miden de 1 a 10, donde 1 significa totalmente infeliz y 10 totalmente feliz. Las barras representan el porcentaje de hogares de ese decil que respondieron con cada calificación del 1 al 10. Se pondera por factores de expansión.

Fuente: ENEMDU - Diciembre 2013-2014.

pregunta, esta se puede considerar como una autoevaluación de la situación económica del hogar en términos absolutos, es decir, sin compararse con nadie.

En el segundo caso, el informante es inducido a imaginar una escala discreta del 1 al $10^{8}$, en la cual clasifica al resto de hogares desde los menos pobres a los más pobres. Posteriormente, el informante se autoclasifica en un punto de esta escala, por lo que esta medida se puede interpretar como una percepción relativa del estatus económico o, equivalentemente, como una proxy de comparación social. Algo a resaltar de la pregunta referida, es que el informante por sí mismo es quien considera a los hogares de referencia con los que se compara. De este modo, los puntos de referencia de los hogares más pobres y más ricos pueden diferir en términos objetivos, con lo que no resultaría extraño encontrar hogares que se consideran extremadamente pobres o ricos en los deciles extremos de ingresos.

En la Figura 3 se muestra gráficamente el porcentaje de hogares que responden a las opciones de las preguntas sobre percepción de la pobreza en cada decil de ingresos. Tanto en el caso absoluto como en el relativo, las evaluaciones que realizan los hogares acerca de su estatus económico son consistentes con su nivel de ingresos.

\footnotetext{
${ }^{8}$ Originalmente, la variable de percepción relativa del estatus socioeconómico es una escala de 0 a 10, en donde 0 se ubican los más pobres y en 10 los más ricos. Para efectos del análisis se agrupan las categorías 0 y 1 , y se invierte el sentido de la variable para ser interpretada como percepción relativa de pobreza, de modo que los coeficientes se interpreten en el mismo sentido que la percepción económica absoluta.
} 
En el caso de la percepción absoluta se puede destacar que en los deciles más bajos, el porcentaje de hogares que no se consideran pobres, crece en menor medida que en los deciles más altos. Este comportamiento se observa también con el ingreso promedio de los deciles (ver Figura 4), lo cual de cierto modo indicaría que la percepción absoluta de pobreza está ligada al nivel real de ingresos que posee cada hogar. A pesar de ello, no deja de ser llamativo que de los hogares que se encuentran en el decil de ingresos más alto, el 24,7\% se considere pobre. En el caso de que la pregunta estrictamente evalúe una condición absoluta de pobreza, esto podría deberse a que su nivel de ingresos no es suficiente como para cubrir sus gastos mensuales. Sin embargo, esta hipótesis no es posible evaluar con la información disponible ${ }^{9}$, razón por la cual no se descarta un componente de relatividad en la pregunta.

En cuanto a la percepción relativa de la pobreza, proxy de comparación social, se nota una tendencia positiva a lo largo de todos los deciles. Esto muestra que los hogares no se están comparando con los hogares de su misma condición económica, ya que en dicho caso se observaría una distribución similar de las opciones de respuesta en todos los deciles. Es más, en el último decil, el salto de la tendencia es más marcado, lo cual puede reflejar una especie de concientización del estatus económico de los hogares más ricos al compararse frente al resto de la sociedad.

Figura 3: Percepción absoluta y relativa de pobreza según deciles de ingreso.
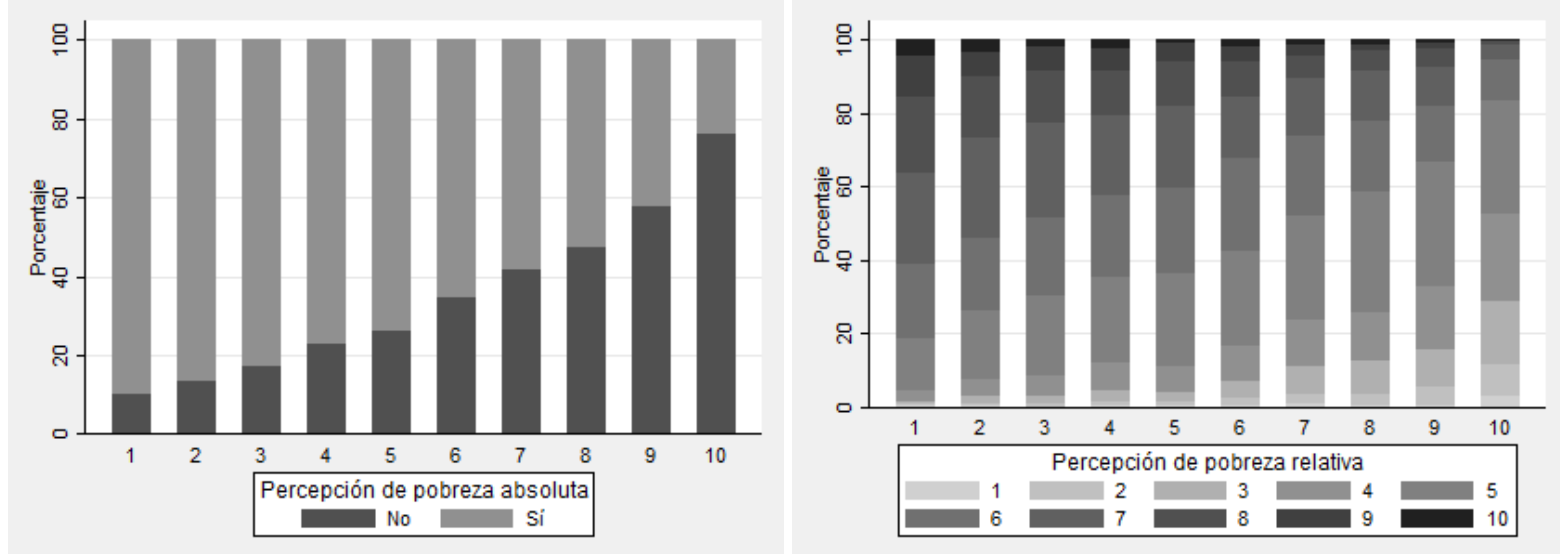

Nota: El eje de las abscisas representa los deciles del ingreso per cápita familiar. La percepción de pobreza relativa se mide de 1 a 10, donde 1 significa no pobre y 10 significa pobre. Las barras representan el porcentaje de hogares de ese decil que respondieron con la opción detallada en las leyendas de cada gráfico. Se pondera por factores de expansión.

Fuente: ENEMDU - Diciembre 2013-2014.

\footnotetext{
${ }^{9}$ En el caso de disponer información sobre los gastos que el hogar realiza en el mes, se podría hacer una comparación con el nivel de ingresos para determinar si los hogares que se consideran pobres son aquellos que no logran cubrir sus necesidades con los recursos disponibles.
} 


\subsubsection{Aspiraciones}

La proxy de aspiraciones que se usa en el presente trabajo proviene de una pregunta sobre el nivel de ingresos mínimos que el informante cree que sería necesario para que un hogar como el suyo llegue a fin de mes. A priori, esta pregunta podría interpretarse como un umbral mínimo de aspiraciones, ya que, al especificar que el objetivo es solamente llegar a fin de mes, de cierto modo se le impide al informante pensar en un nivel de ingresos que le permita adquirir bienes lujosos o suntuarios.

Con esto en consideración, en la Figura 4 se puede observar que el nivel de aspiraciones aumenta a medida que un hogar se sitúa en una condición económica más favorable. En parte, esto mostraría que las condiciones bajo las cuales vive un hogar de un decil alto (e.g. vivienda más cara, servicios más caros, educación privada, etc.), le obliga a requerir de un ingreso mayor para llegar a fin de mes.

No obstante, a pesar de que las aspiraciones son crecientes en los deciles del ingreso, su tendencia crece en menor grado que el promedio del ingreso per cápita del hogar. Es decir, a medida que se consideran deciles altos, el ratio ingreso-aspiraciones va disminuyendo, lo cual se puede interpretar como una "concientización" del estatus socioeconómico.

Finalmente, el hecho de que las aspiraciones sean menores al ingreso del hogar en el último decil (el ratio ingreso / aspiraciones es de 1,18), es una razón adicional para interpretar a la proxy de aspiraciones como un umbral mínimo, ya que muestra que los hogares más ricos están conscientes de lograr cubrir las necesidades que consideran como mínimas.

Para analizar en mayor detalle la proxy de aspiraciones empleada, se estimó la relación entre el nivel de aspiraciones y el ingreso per cápita del hogar. Asimismo, se analizó por separado cómo varían las aspiraciones cuando el hogar se considera pobre en términos absolutos y relativos. Posteriormente, para mitigar el sesgo por variables omitidas, se incluyeron varias características observables y efectos fijos (modelo 1).

En la Tabla A.5 se muestran las estimaciones para varios modelos de aspiraciones. En el primer modelo se puede notar una asociación positiva y estadísticamente significativa entre las aspiraciones y el ingreso ${ }^{10}$; específicamente, un aumento del $1 \%$ en el nivel de ingresos, ceteris paribus, se asocia con un aumento de 0,57\% en el nivel de aspira-

\footnotetext{
${ }^{10}$ Inicialmente, la pregunta de aspiraciones económicas indaga sobre las necesidades del hogar. Para efectos de análisis y comparabilidad con la variable de ingresos per cápita del hogar, las aspiraciones también se expresan en términos per cápita.
} 
Figura 4: Ingreso del hogar y aspiraciones según deciles de ingreso.

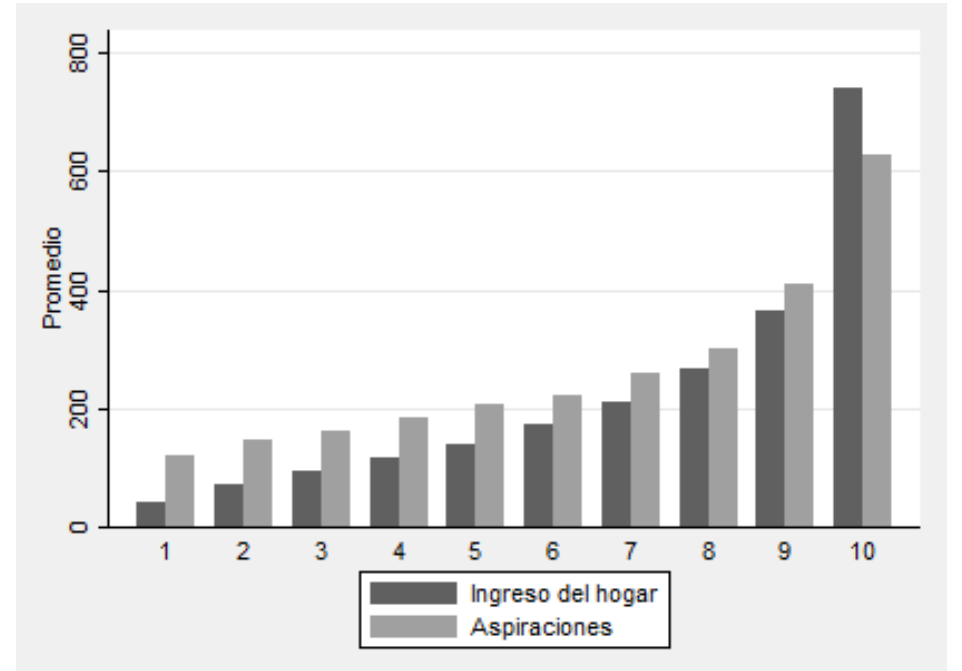

Nota: Ambas distribuciones se expresan en dólares de 2013. Se pondera por factores de expansión.

Fuente: ENEMDU - Diciembre 2003-2014.

ciones. Esta relación es consistente con lo mostrado en la Figura 4, en donde se nota que las aspiraciones aumentan con el ingreso, aunque en menor grado. Luego, en los modelos (2) y (3) se encontró una relación negativa entre las aspiraciones y las percepciones de pobreza absoluta y relativa; no obstante, al considerar al mismo tiempo al ingreso y las percepciones de pobreza, la magnitud de los coeficientes de los dos últimos casos se reduce a una décima parte.

Posteriormente, cuando se incluyen otros controles, las variables de percepción pierden significancia estadística, lo que permite concluir que el hecho de que un hogar perciba ser pobre o no, no incide en el nivel de aspiraciones; en su lugar, el nivel de aspiraciones de un hogar viene asociado más bien con el ingreso efectivo: en el modelo (6) se observa que, ceteris paribus, un aumento del $1 \%$ en el nivel de ingresos, se encuentra asociado con un aumento de $0,27 \%$ en el nivel de aspiraciones.

De este modo, se puede concluir que en el contexto analizado, las aspiraciones económicas mínimas son crecientes en el ingreso. Además, el hecho de que las variables de percepción no tengan relevancia sobre el nivel de aspiraciones puede deberse a que el ingreso mínimo necesario que los hogares reportan está atado a sus condiciones económicas reales. Esta aseveración se puede respaldar con la forma en como se plantea la pregunta, ya que al decirle al informante que piense en un hogar como el suyo, posiblemente evite que tome en consideración necesidades o preferencias particulares. 


\subsection{Estudios de eventos}

Dado que la fuente de información posee una estructura de panel, es posible analizar cómo cambia el bienestar global y financiero de un hogar entre 2013 y 2014, cuando experimenta un cambio en alguna característica durante este periodo. A pesar de que el panel se compone solamente de dos puntos en el tiempo, es posible tener un panorama sobre el impacto en el corto plazo de un cambio en alguna condición. Los eventos analizados son cambios de: decil del ingreso per cápita del hogar, decil del ingreso laboral del jefe de hogar y condición de actividad del jefe de hogar ${ }^{11}$.

\subsubsection{Cambio en el ingreso per cápita del hogar}

En primer lugar, se analiza cómo varían el bienestar financiero y global, cuando un hogar pasa a un decil de ingresos per cápita del hogar más alto, más bajo, o si permanece en el mismo. En la Figura 5a se puede notar que el bienestar financiero de todos los hogares se redujo en 0,14 puntos (de 5.77 a 5.64) entre 2013 y 2014. No obstante, los hogares que experimentaron una movilidad económica descendente fueron los que presentaron la mayor reducción del bienestar (0,34 puntos), seguidos de los que permanecieron en el mismo decil (0,22 puntos). Solamente el grupo que pasó a un decil más alto mostró un crecimiento de 0,13 puntos en el bienestar financiero. Al realizar una regresión del cambio en el bienestar sobre los tres grupos de hogares y tomando como referencia a los que permanecen en el mismo decil (Tabla A.6, regresión I), se pudo notar que los cambios en el bienestar son estadísticamente diferentes, con respecto a los que pasan a un decil menor (nivel de significancia de 10\%), y los que pasan a un decil mayor (nivel de significancia de 1\%).

Por su parte, en la Figura 5b se puede notar que las variaciones del bienestar global son similares para todos los grupos de movilidad, conclusión que se comprueba también estadísticamente (Tabla A.6, regresión I). Esto refleja que si bien, en un corte transversal, el bienestar global y el ingreso están relacionados positivamente, cuando se analiza la variación del bienestar para un mismo conjunto de hogares en función de un cambio en su estatus económico, no existe una relación clara como en el caso del bienestar financiero.

En la Figura 5 también se puede ver que en cuanto a los niveles de bienestar

\footnotetext{
${ }^{11} \mathrm{Si}$ bien se realiza una exposición gráfica de cada resultado, también se efectuaron regresiones con el fin de determinar si las diferencias en los cambios del bienestar difieren de manera significativa entre hogares que experimentan distintos eventos. La Tabla A.6 contiene las estimaciones de estos modelos.
} 
Figura 5: Cambio en el bienestar según cambio en el decil de ingresos.

(a) Bienestar financiero

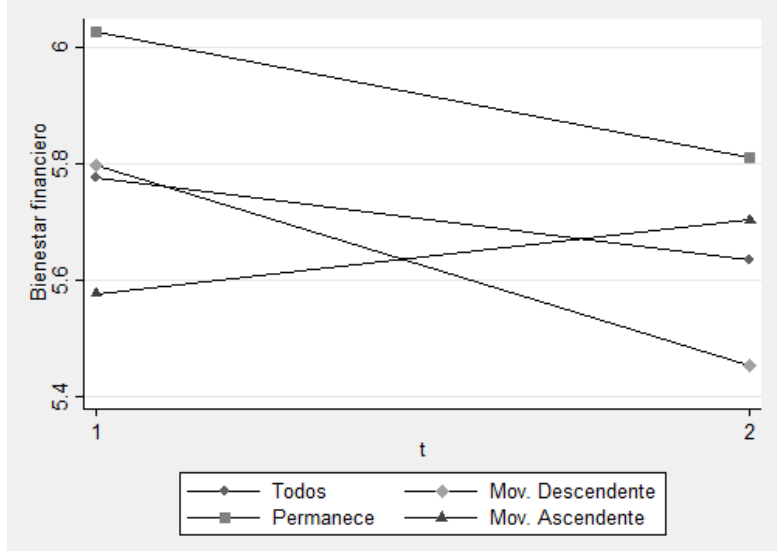

(b) Bienestar global

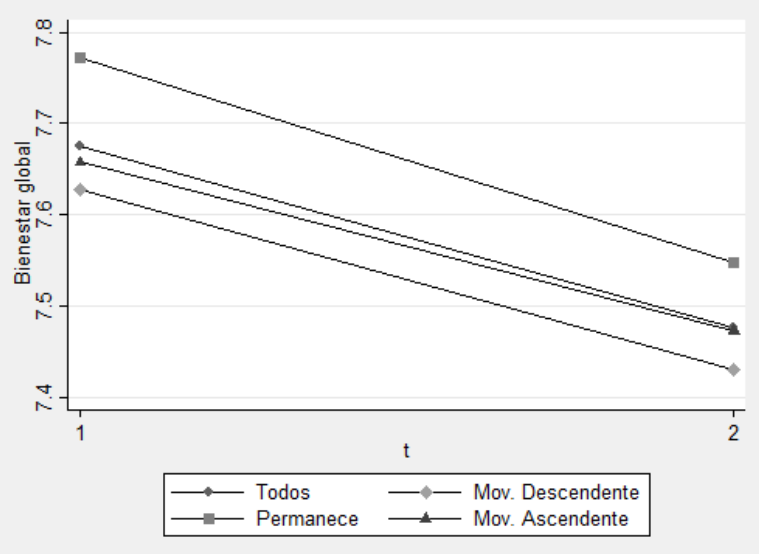

Fuente: ENEMDU - Diciembre 2013-2014.

financiero y global, aquellos hogares que permanecen en el mismo decil poseen un nivel por encima de los hogares móviles. En este sentido, la Figura 6 muestra las variaciones del bienestar considerando otra caracterización para la movilidad económica. En primer lugar, se separan a los hogares que permanecen en el mismo decil en: aquellos que permanecen en el quinto decil o menos (deciles bajos) y aquellos que permanecen en el sexto decil o más (deciles altos) ${ }^{12}$. Luego, los hogares que experimentan movilidad ascendente son solamente aquellos que se mueven hacia el sexto decil o más en el año final; mientras que en el grupo de movilidad descendente están solamente aquellos que caen a partir del quinto decil hacia abajo.

Con esto en consideración, se puede notar que los hogares que permanecen en los deciles altos poseen los niveles de bienestar financiero y global mayores al resto; mientras que aquellos que permanecen en los deciles bajos poseen los menores niveles de bienestar. En el primer caso, esto puede obedecer a una mayor percepción de bienestar generada por su estabilidad económica; y en el segundo, a una frustración que sienten los hogares al no poder salir de su situación inicial y tener que convivir en condiciones más precarias.

En lo que respecta a los hogares que ascienden hacia los deciles más altos, se puede destacar que sus niveles de bienestar financiero en el año final, si bien aumentan, no logran alcanzar los niveles de bienestar de quienes permanecen en los deciles altos. Posiblemente, esto se deba a que no cuentan aún con una estabilidad económica que

\footnotetext{
${ }^{12} \mathrm{La}$ terminología de deciles altos y bajos es usada para describir los resultados de mejor manera. La clasificación se realizó con el fin de obtener dos grupos de igual tamaño, mas no representa un criterio subjetivo sobre la determinación de cuándo un decil puede considerarse como bajo o alto.
} 
les permita sentirse lo suficientemente seguros en términos financieros. Por lo tanto, a medida que su condición económica se estabilice, es probable que muestren los mismos patrones de bienestar que los hogares que permanecen en los deciles altos ${ }^{13}$. Finalmente, los niveles de bienestar global no muestran un patrón distinto en cuanto a sus variaciones, tal como ocurrió en el caso inicial.

Figura 6: Cambio en el bienestar según cambio en deciles altos y bajos de ingresos.

(a) Bienestar financiero

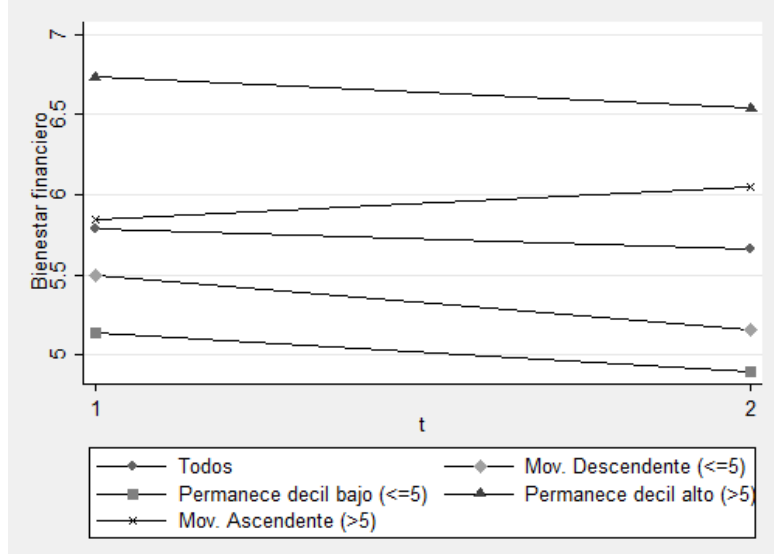

(b) Bienestar global

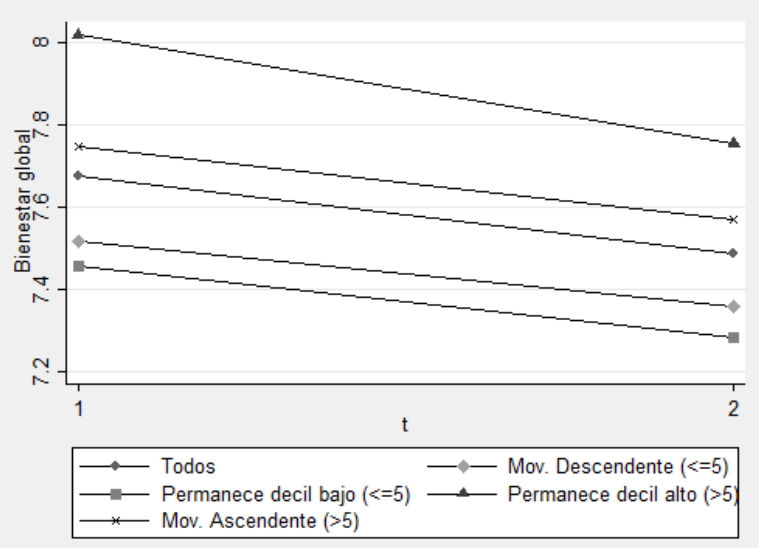

Nota: Se presenta la movilidad descendente hacia deciles bajos (quinto decil o menos) y la movilidad ascendente hacia deciles altos (sexto decil o más).

Fuente: ENEMDU - Diciembre 2003-2014.

\subsubsection{Cambio en el ingreso laboral del jefe de hogar}

Con el fin de determinar si la relación entre el bienestar y el ingreso hallada previamente es similar si solo se consideran los ingresos de ciertos miembros del hogar, se analizaron varios casos $^{14}$. En la Figura 7 se muestran las variaciones del bienestar financiero y global cuando cambia el ingreso laboral del jefe del hogar ${ }^{15}$, pudiéndose notar que existe una relación con ambos tipos de bienestar. El hecho de que el jefe del hogar pase a un decil de ingresos laborales menor (mayor), hace que su bienestar global descienda en 0,39 (aumente en 0,13), con respecto a los que permanecen en el mismo decil de ingresos laborales; ambas diferencias resultan ser estadísticamente significativas

\footnotetext{
${ }^{13}$ Una limitación de la corta longitud temporal del panel, es que no se pueden evaluar la adaptación y bienestar de los hogares en el mediano y largo plazo.

${ }^{14}$ En la Figura A.1 y Figura A.2 se presentan los resultados obtenidos cuando varían los ingresos de miembros no jefes de hogar y de las mujeres del hogar. En ambos casos los patrones son similares a lo que ocurre con el ingreso laboral del jefe de hogar (Figura 7).

${ }^{15}$ Se descartaron a los jefes con un ingreso laboral nulo en ambos periodos, por tratarse de individuos que no pertenecen a la población económicamente activa.
} 
al 1\% y 10\%, respectivamente (Tabla A.6, regresión III).

El hecho de que un cambio del ingreso laboral del jefe afecte al bienestar general reportado, puede deberse a que los eventos que afectan al jefe de hogar, quien es por lo general el informante, pueden deteriorar su bienestar, a diferencia de lo que ocurre cuando se analiza el ingreso per cápita del hogar. Es decir, una persona puede sentirse menos satisfecha con su vida si le ocurre algún evento como una caída de sus ingresos laborales, aunque si considera los recursos que aportan los demás miembros del hogar, su bienestar posiblemente no se vea deteriorado porque se daría cuenta de que las necesidades económicas del hogar podrían ser cubiertas.

Figura 7: Cambio en el bienestar según cambio en deciles del ingreso laboral del jefe de hogar.

(a) Bienestar financiero

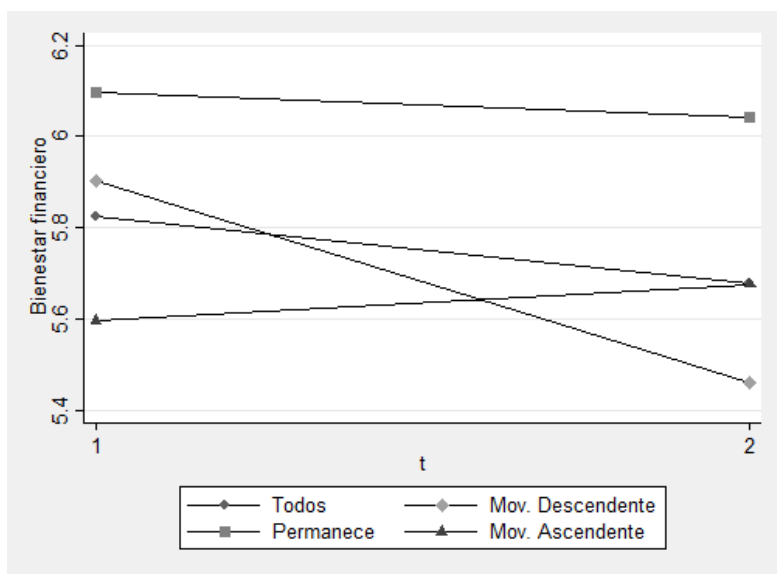

(b) Bienestar global

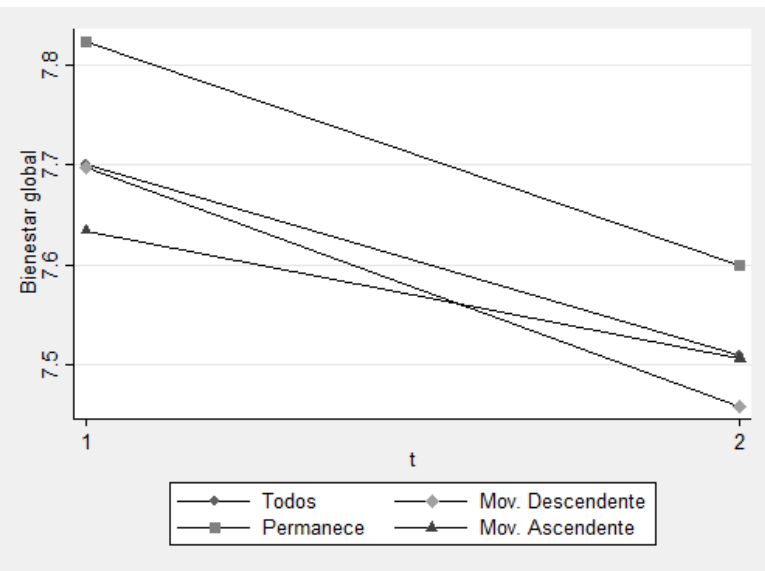

Nota: Se descartan los casos en los que el jefe de hogar no percibe ingresos laborales en ambos periodos. Fuente: ENEMDU - Diciembre 2003-2014.

\subsubsection{Cambio en la condición de actividad del jefe de hogar}

El propósito de la Figura 8 es analizar cómo cambia el bienestar del hogar, cuando el jefe experimenta un cambio en su condición de actividad. Para este propósito, se excluyeron a los hogares cuyos jefes estuvieron económicamente inactivos en los dos periodos.

En cuanto al bienestar financiero, se puede notar que las tendencias son similares a las halladas en los cambios de ingreso. Destacan principalmente las tendencias opuestas de aquellas personas que encuentran un empleo versus las que pierden, con una diferencia estadísticamente significativa de 0,60 (Tabla A.6, regresión IV). Esto refleja que el hecho 
de caer en el desempleo conlleva a un deterioro importante en el bienestar, que incluso supera a la caída del bienestar de los que permanecen sin empleo. No obstante, se debe tener en cuenta que en cuanto a niveles, aquellos que recién experimentaron una pérdida de empleo siguen presentando un bienestar financiero mayor al de los que continúan sin empleo, aunque posiblemente, estos niveles podrían equipararse si en los próximos periodos continúan sin hallar un empleo .

Figura 8: Bienestar y cambio en la condición de actividad del jefe de hogar.

(a) Bienestar financiero

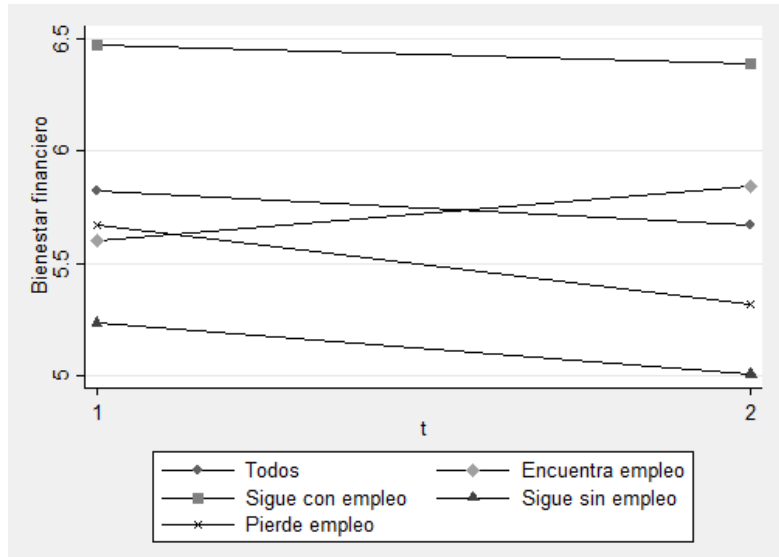

(b) Bienestar global

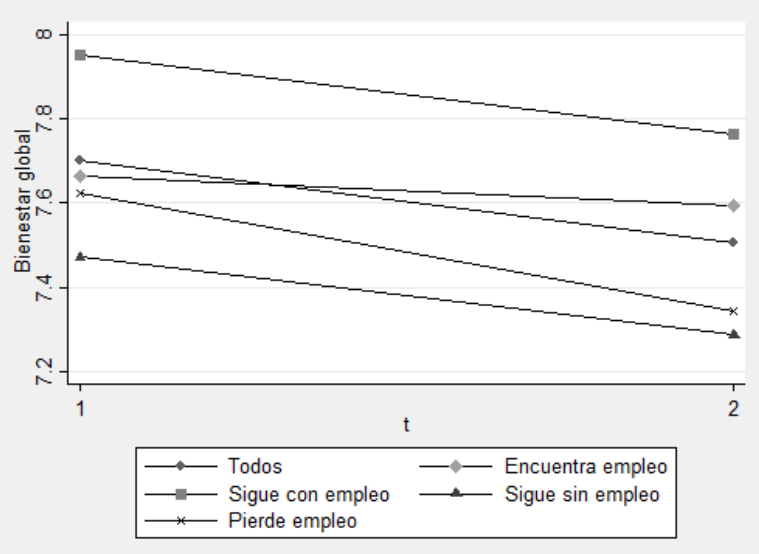

Nota: Se descartan los hogares cuyos jefes de hogar no pertenecen a la población económicamente activa.

Fuente: ENEMDU - Diciembre 2003-2014.

\subsection{Bienestar financiero y global: relación con factores económicos objetivos y subjetivos}

A modo de resumen, en las anteriores secciones se analizaron varios aspectos concernientes a las dimensiones de análisis del presente trabajo. En primer lugar se realizó un breve análisis del cambio en la distribución del ingreso desde una perspectiva anónima y no anónima entre 2013 y 2014. En general, el ingreso aumentó y la desigualdad disminuyó en el periodo de análisis. No obstante, al analizar la evolución del ingreso per cápita de los hogares a través de una matriz de transición entre quintiles de ingreso, se constató una movilidad ascendente y descendente importante.

En segundo lugar, se pudo constatar que existe una relación positiva y estadísticamente significativa entre el ingreso y el bienestar subjetivo financiero y global, cuando se analiza un punto específico del tiempo. Esto va acorde a la evidencia empírica hallada en otros países, en donde la información empleada posee esta estructura. Sin embargo, esto no 
descarta la posible influencia de terceros factores que estarían generando un problema de endogeneidad en la relación del bienestar subjetivo con el ingreso.

Luego se encontró que las variables de percepción económica de los hogares guardan consistencia con el nivel de ingreso de los hogares, y que la proxy de aspiraciones empleada puede interpretarse como un umbral mínimo necesario para cubrir las necesidades mínimas del hogar.

En tercer lugar, se explotó la estructura de panel disponible para analizar cómo varía el bienestar de los hogares cuando experimentan cambios en aspectos como: el ingreso per cápita del hogar, el ingreso laboral del jefe de hogar y la condición de actividad del jefe de hogar. Mediante esto se pudo determinar que el bienestar financiero muestra una relación consistente con los cambios en la condición económica. Sin embargo, con respecto al bienestar global, un cambio en el estatus económico no necesariamente se traduce en un cambio de bienestar diferente al resto de hogares.

En esta sección se analiza de manera conjunta cómo el ingreso -interpretado como una variable objetiva de estatus económico-, las variables de percepción económica absoluta/relativa, y las aspiraciones, se relacionan con el bienestar subjetivo financiero y global. Para aislar de mejor manera la relación entre estos factores y el bienestar subjetivo, se incluyeron características que varían en el tiempo, y se aprovechó la estructura de panel para controlar por efectos fijos (modelo 2). De este modo, se espera corregir en el mayor grado posible el sesgo por variables omitidas, con el fin de aportar con evidencia empírica más robusta en lo que respecta a la relación entre el bienestar subjetivo y los factores mencionados.

\subsubsection{Bienestar financiero}

En la Tabla 1 se muestran las estimaciones para varios modelos del bienestar financiero. En las cuatro primeras columnas se analiza cómo el bienestar financiero se relaciona con los indicadores económicos y de percepción sin incluir controles adicionales, a excepción de la dimensión temporal. En todos los casos, las relaciones son estadísticamente significativas al 1\%, aunque solo en los tres primeros el sentido de los coeficientes son consistentes a lo esperado: el bienestar financiero se relaciona positivamente con un mayor ingreso y una menor percepción absoluta y relativa de pobreza. Con respecto a las aspiraciones, el signo negativo inicial se da por un sesgo por variables omitidas, debido a que no se incluye al ingreso como control. 
Tabla 1: Estimación del modelo de bienestar financiero.

\begin{tabular}{|c|c|c|c|c|c|c|c|c|c|}
\hline VARIABLES & $(1)$ & (2) & $(3)$ & (4) & (5) & (6) & (7) & (8) & $(9)$ \\
\hline Logaritmo & $0,838^{* * *}$ & & & & $0,430 * * *$ & $0,427^{* * *}$ & $0,275^{* * *}$ & $0,239^{* * *}$ & $0,203^{* * *}$ \\
\hline ingreso & $(0,0210)$ & & & & $(0,0277)$ & $(0,0280)$ & $(0,0482)$ & $(0,0511)$ & $(0,0603)$ \\
\hline Considera_pobre & & $-1,573^{* * *}$ & & & $-0,411 * * *$ & $-0,425 * * *$ & $-0,233^{* * *}$ & $-0,227 * * *$ & $-0,248^{* * *}$ \\
\hline (absoluto) & & $(0,0376)$ & & & $(0,0469)$ & $(0,0476)$ & $(0,0701)$ & $(0,0701)$ & $(0,0793)$ \\
\hline Considera_pobre & & & $-0,548^{* * *}$ & & $-0,403 * * *$ & $-0,404 * * *$ & $-0,354^{* * *}$ & $-0,351 * * *$ & $-0,327 * * *$ \\
\hline (relativo) & & & $(0,0101)$ & & $(0,0134)$ & $(0,0137)$ & $(0,0190)$ & $(0,0190)$ & $(0,0219)$ \\
\hline Logaritmo & & & & $0,593^{* * *}$ & $-0,0911^{* * *}$ & $-0,0818^{* * *}$ & $-0,0257$ & $-0,00114$ & 0,0382 \\
\hline aspiraciones & & & & $(0,0253)$ & $(0,0298)$ & $(0,0305)$ & $(0,0508)$ & $(0,0537)$ & $(0,0617)$ \\
\hline & & & & & & $-0,163^{* * *}$ & & & \\
\hline Mujer & & & & & & $(0,0393)$ & & & \\
\hline Minoría & & & & & & $-0,0422$ & & & \\
\hline étnica & & & & & & $(0,0506)$ & & & \\
\hline $\begin{array}{l}\text { Condición de ac- } \\
\text { tividad (Ref: Ade- } \\
\text { cuado) }\end{array}$ & & & & & & & & & \\
\hline Inadecuado/ & & & & & & & & $-0,155^{* *}$ & $-0,178^{* *}$ \\
\hline Desempleado & & & & & & & & $(0,0767)$ & $(0,0854)$ \\
\hline Inactivo & & & & & & & & $-0,191$ & $-0,168$ \\
\hline & & & & & & & & $(0,120)$ & $(0,135)$ \\
\hline \multicolumn{10}{|l|}{$\begin{array}{l}\text { Nivel de instrucción } \\
\text { (Ref: Ninguna) }\end{array}$} \\
\hline Primaria & & & & & & & & $\begin{array}{l}0,138 \\
(0,157)\end{array}$ & $\begin{array}{l}0,110 \\
(0,223)\end{array}$ \\
\hline Secundaria & & & & & & & & $\begin{array}{l}0,162 \\
(0,192)\end{array}$ & $\begin{array}{l}0,161 \\
(0,255)\end{array}$ \\
\hline Superior & & & & & & & & $\begin{array}{l}0,284 \\
(0,264)\end{array}$ & $\begin{array}{l}0,324 \\
(0,316)\end{array}$ \\
\hline Soltero/Solo & & & & & & & & $\begin{array}{l}0,00774 \\
(0,133)\end{array}$ & $\begin{array}{c}-0,0420 \\
(0,148)\end{array}$ \\
\hline Edad & & & & & & & & $\begin{array}{l}-0,0237 \\
(0,0614)\end{array}$ & $\begin{array}{l}0,0196 \\
(0.0768)\end{array}$ \\
\hline $\operatorname{Edad}^{2}$ & & & & & & & & $\begin{array}{l}0,000178 \\
(0,000513)\end{array}$ & $\begin{array}{c}-7,79 \mathrm{E}-05 \\
(0,000687)\end{array}$ \\
\hline \multicolumn{10}{|l|}{$\begin{array}{l}\text { Percepción democra- } \\
\text { cia (Ref: Muy de } \\
\text { acuerdo) }\end{array}$} \\
\hline Poco de acuerdo & & & & & & & & & $\begin{array}{l}0,0317 \\
(0,0647)\end{array}$ \\
\hline En desacuerdo & & & & & & & & & $\begin{array}{l}0,0572 \\
(0,0776)\end{array}$ \\
\hline Seguridad & & & & & & & & & $\begin{array}{l}0,218^{* * *} \\
(0,0419)\end{array}$ \\
\hline Confianza & & & & & & & & & $\begin{array}{l}0,122^{* * *} \\
(0,0322)\end{array}$ \\
\hline Tamaño del hogar & & & & & & & & $\begin{array}{l}0,0435 \\
(0,0268)\end{array}$ & $\begin{array}{l}0,0507 \\
(0,0309)\end{array}$ \\
\hline Práctica de deporte & & & & & & & & $\begin{array}{l}0,0833 \\
(0,0644)\end{array}$ & $\begin{array}{l}0,0765 \\
(0,0694)\end{array}$ \\
\hline Año 2014 & $-0,239 * * *$ & $-0,189 * * *$ & $-0,0961^{* * *}$ & $-0,187^{* * *}$ & $-0,164^{* * *}$ & $-0,165^{* * *}$ & $-0,149 * * *$ & $-0,147 * * *$ & $-0,175^{* * *}$ \\
\hline & $(0,0365)$ & $(0,0362)$ & $(0,0343)$ & $(0,0378)$ & $(0,0339)$ & $(0,0338)$ & $(0,0332)$ & $(0,0384)$ & $(0,0448)$ \\
\hline Constante & $1,642^{* * *}$ & $6,838^{* * *}$ & $8,888 * * *$ & $2,688 * * *$ & $6,693^{* * *}$ & $6,681^{* * *}$ & $6,722^{* * *}$ & $7,207 * * *$ & $4,469 * *$ \\
\hline & $(0,107)$ & $(0,0349)$ & $(0,0606)$ & $(0,133)$ & $(0,170)$ & $(0,184)$ & $(0,333)$ & $(1,833)$ & $(2,189)$ \\
\hline Dummies provincia & No & No & No & No & No & Sí & No & No & No \\
\hline Efectos fijos & No & No & No & No & No & No & Sí & Sí & Sí \\
\hline Observaciones & 18.612 & 18.612 & 18.610 & 18.605 & 18.603 & 18.603 & 18.603 & 18.560 & 16.145 \\
\hline R-cuadrado & 0,113 & 0,131 & 0,211 & 0,046 & 0,240 & 0,245 & 0,090 & 0,091 & 0,101 \\
\hline
\end{tabular}

Nota: Errores estándar robustos entre paréntesis. ${ }^{* * *} \mathrm{p}<0,01,{ }^{*} \mathrm{p}<0,05,{ }^{*} \mathrm{p}<0,1$. Resultados ajustados por factor de expansión.

Fuente: ENEMDU - Diciembre 2003-2014. 
Cuando se incluye en un mismo modelo a los cuatro factores a la vez (especificación 5), se puede notar una disminución en la magnitud de los tres primeros coeficientes, lo cual refleja que estos factores inicialmente están correlacionados ${ }^{16}$. En cuanto a las aspiraciones, se puede observar que al incluir el resto de factores, su relación con el bienestar subjetivo pasa a ser negativa y estadísticamente significativa.

En el sexto modelo se incluyen características observables del jefe de hogar que no varían en el tiempo como su género, etnia y provincia ${ }^{17}$. El objetivo es determinar cuán importantes son las variables observables invariantes en el tiempo, con respecto al componente de heterogeneidad individual global, el cual está compuesto también por variables no observables que pueden considerarse invariantes en el tiempo como la personalidad, habilidades, etc. Al añadir las tres características (especificación 6), los coeficientes asociados a las variables económicas y de percepción varían levemente. Al contrario, cuando se incluyen efectos fijos (especificación 7), las estimaciones puntuales de los coeficientes varían sustancialmente, e inclusive, la significancia estadística de las aspiraciones económicas se pierde considerando un nivel del $10 \%$.

Finalmente, en las especificaciones 8 y 9 se incluyen otras características que, de acuerdo a la literatura indagada, pueden influir sobre el bienestar y que son variantes en el tiempo ${ }^{18}$. No obstante, su inclusión no afectó la estimación de los coeficientes de los cuatro factores iniciales.

Como una breve conclusión, se puede destacar que la inclusión de efectos fijos es lo que más influye en la relación de los factores económicos y de percepción con el bienestar financiero; y que son las características inobservables o difíciles de medir como la personalidad y habilidades, las que tendrían mayor relevancia. Adicionalmente, se puede notar una relación positiva entre el nivel de ingresos y el bienestar financiero, aunque si se considera la última especificación, la magnitud no resulta ser importante: cuando el ingreso aumenta en 10\%, ceteris paribus, la evaluación del bienestar financiero aumenta en 0,0203 puntos. En cuanto a la percepción de la pobreza, se puede destacar que el aumento de un punto en la percepción relativa de pobreza, ceteris paribus, se relaciona con una caída de 0.327 puntos en el bienestar financiero, y que aquellas personas que se perciben como pobres sin compararse con nadie, ceteris paribus, poseen un nivel de

\footnotetext{
${ }^{16}$ En la sección 2.2 se comprobó la relación entre las variables de percepción económica, aspiraciones y el ingreso

${ }^{17} \mathrm{Si}$ bien, un hogar puede mudarse a otra provincia de un año a otro, estos casos no se incluyen en el panel de hogares, puesto que las visitas se realizan sobre los mismos hogares.

${ }^{18}$ A diferencia de la especificación 9, la especificación 8 no incluye las variables que miden la percepción de la democracia, seguridad, y confianza en el gobierno. Esto con el fin de no perder observaciones por los datos perdidos de las variables mencionadas.
} 
bienestar menor en 0,248 puntos, con respecto a quienes no perciben sentirse pobres. Finalmente, se puede notar que las aspiraciones económicas no se relacionan con el bienestar financiero. Con respecto al resto de variables incluidas en los modelos, el sentido de las estimaciones puntuales de los coeficientes guarda consistencia con la literatura indagada. Sin embargo, solamente en los casos de la condición de actividad, confianza en instituciones públicas y seguridad se hallaron relaciones estadísticamente significativas. En el primer caso, se puede notar que estar desempleado o en un empleo inadecuado hace que el bienestar financiero sea menor en 0,178 puntos, en relación a aquellos que poseen un empleo adecuado. De modo similar, el bienestar financiero es mayor para aquellos hogares que poseen una mayor percepción de seguridad y de confianza con el gobierno. La ausencia de un mayor número de relaciones estadísticamente significativas puede deberse a la poca variabilidad de las variables explicativas por la corta longitud temporal del panel.

\subsubsection{Bienestar global}

En la Tabla 2 se muestran las estimaciones correspondientes al modelo de bienestar global considerando las mismas variables explicativas del modelo de bienestar financiero. En las cinco primeras especificaciones se obtienen conclusiones similares al bienestar financiero: al incluir las cuatro variables a la vez (especificación 5), las magnitudes de los coeficientes de las tres primeras variables se reducen y el sentido del coeficiente de aspiraciones económicas pasa a ser negativo. Esto último muestra nuevamente el sesgo por variables omitidas de la especificación 4, en donde no se toma en cuenta el hecho de que las aspiraciones económicas aumentan con el nivel de ingresos.

En la especificación 6 se añaden características observables invariantes en el tiempo. En este caso, los coeficientes de las variables de ingreso y percepción no muestran alteración. Sin embargo, cuando se controlan por efectos fijos (especificación 7), el logaritmo del ingreso y la percepción absoluta de pobreza pierden significatividad estadística. Posteriormente, cuando se controlan por características variantes en el tiempo (especificaciones 8 y 9), los coeficientes de los factores de interés permanecen igual, con lo cual se concluye nuevamente que la heterogeneidad individual es lo que más incide en la relación entre el bienestar global y las dimensiones analizadas. 
Tabla 2: Estimación del modelo de bienestar global.

\begin{tabular}{|c|c|c|c|c|c|c|c|c|c|}
\hline VARIABLES & (1) & $(2)$ & (3) & $(4)$ & (5) & (6) & (7) & (8) & (9) \\
\hline Logaritmo & $0,264^{* * *}$ & & & & $0,115^{* * *}$ & $0,120^{* * *}$ & 0,0381 & 0,00736 & 0,0335 \\
\hline ingreso & $(0,0161)$ & & & & $(0,0226)$ & $(0,0228)$ & $(0,0404)$ & $(0,0424)$ & $(0,0493)$ \\
\hline Considera_pobre & & $-0,605^{* * *}$ & & & $-0,160^{* * *}$ & $-0,174^{* * *}$ & $-0,0234$ & $-0,0173$ & $-0,0394$ \\
\hline (absoluto) & & $(0,0282)$ & & & $(0,0372)$ & $(0,0377)$ & $(0,0586)$ & $(0,0585)$ & $(0,0629)$ \\
\hline Considera_pobre & & & $-0,221 * * *$ & & $-0,183^{* * *}$ & $-0,188^{* * *}$ & $-0,163^{* * *}$ & $-0,161 * * *$ & $-0,127 * * *$ \\
\hline (relativo) & & & $(0,00798)$ & & $(0,0107)$ & $(0,0108)$ & $(0,0161)$ & $(0,0161)$ & $(0,0178)$ \\
\hline Logaritmo & & & & $0,153^{* * *}$ & $-0,0951^{* * *}$ & $-0,103^{* * *}$ & $-0,217^{* * *}$ & $-0,216^{* * *}$ & $-0,234^{* * *}$ \\
\hline aspiraciones & & & & $(0,0188)$ & $(0,0244)$ & $(0,0249)$ & $(0,0433)$ & $(0,0446)$ & $(0,0498)$ \\
\hline Mujer & & & & & & $\begin{array}{l}-0,164 * * * \\
(0,0311)\end{array}$ & & & \\
\hline $\begin{array}{l}\text { Minoría } \\
\text { étnica }\end{array}$ & & & & & & $\begin{array}{l}0,0264 \\
(0,0406)\end{array}$ & & & \\
\hline $\begin{array}{l}\text { Condición de ac- } \\
\text { tividad (Ref: Ade- } \\
\text { cuado) }\end{array}$ & & & & & & & & & \\
\hline Inadecuado/ & & & & & & & & $-0,143^{* *}$ & $-0,143^{* *}$ \\
\hline Desempleado & & & & & & & & $(0,0615)$ & $(0,0671)$ \\
\hline Inactivo & & & & & & & & $\begin{array}{l}-0,114 \\
(0,101)\end{array}$ & $\begin{array}{l}-0,0844 \\
(0,112)\end{array}$ \\
\hline \multicolumn{10}{|l|}{$\begin{array}{l}\text { Nivel de instrucción } \\
\text { (Ref: Ninguna) }\end{array}$} \\
\hline Primaria & & & & & & & & $\begin{array}{l}0,00324 \\
(0,142)\end{array}$ & $\begin{array}{l}0,0279 \\
(0,208)\end{array}$ \\
\hline Secundaria & & & & & & & & 0,135 & 0,112 \\
\hline & & & & & & & & $(0,172)$ & $(0,233)$ \\
\hline Superior & & & & & & & & 0,275 & 0,255 \\
\hline & & & & & & & & $(0,242)$ & $(0,294)$ \\
\hline Soltero/Solo & & & & & & & & $\begin{array}{l}-0,0100 \\
(0,115)\end{array}$ & $\begin{array}{l}-0,0228 \\
(0,124)\end{array}$ \\
\hline Edad & & & & & & & & $-0,0204$ & 0,0107 \\
\hline & & & & & & & & $(0,0580)$ & $(0,0643)$ \\
\hline $\operatorname{Edad}^{2}$ & & & & & & & & $3,38 \mathrm{E}-05$ & $-0,000267$ \\
\hline & & & & & & & & $(0,000470)$ & $(0,000545)$ \\
\hline \multicolumn{10}{|l|}{$\begin{array}{l}\text { Percepción democra- } \\
\text { cia (Ref: Muy de } \\
\text { acuerdo) }\end{array}$} \\
\hline Poco de acuerdo & & & & & & & & & $\begin{array}{l}0,0146 \\
(0,0531)\end{array}$ \\
\hline \multirow[t]{2}{*}{ En desacuerdo } & & & & & & & & & 0,0696 \\
\hline & & & & & & & & & $(0,0618)$ \\
\hline \multirow[t]{2}{*}{ Seguridad } & & & & & & & & & $0,0591^{*}$ \\
\hline & & & & & & & & & $(0,0348)$ \\
\hline \multirow[t]{2}{*}{ Confianza } & & & & & & & & & $0,211^{* * *}$ \\
\hline & & & & & & & & & $(0,0274)$ \\
\hline \multirow[t]{2}{*}{ Tamaño del hogar } & & & & & & & & 0,00889 & 0,00558 \\
\hline & & & & & & & & $(0,0229)$ & $(0,0251)$ \\
\hline \multirow[t]{2}{*}{ Práctica de deporte } & & & & & & & & 0,0850 & 0,0589 \\
\hline & & & & & & & & $(0,0580)$ & $(0,0623)$ \\
\hline \multirow[t]{2}{*}{ Año 2014} & $-0,231 * * *$ & $-0,219 * * *$ & $-0,183^{* * *}$ & $-0,212^{* * *}$ & $-0,196 * * *$ & $-0,196 * * *$ & $-0,175^{* * *}$ & $-0,159 * * *$ & $-0,142^{* * *}$ \\
\hline & $(0,0278)$ & $(0,0276)$ & $(0,0272)$ & $(0,0280)$ & $(0,0272)$ & $(0,0270)$ & $(0,0277)$ & $(0,0325)$ & $(0,0369)$ \\
\hline \multirow[t]{2}{*}{ Constante } & $6,375^{* * *}$ & $8,085^{* * *}$ & $8,928 * * *$ & $6,878^{* * *}$ & $8,749^{* * *}$ & $8,651^{* * *}$ & $9,558^{* * *}$ & $10,590^{* * *}$ & $8,740^{* * *}$ \\
\hline & $(0,0826)$ & $(0,0264)$ & $(0,0471)$ & $(0,0996)$ & $(0,137)$ & $(0,146)$ & $(0,269)$ & $(1,762)$ & $(1,929)$ \\
\hline Dummies provincia & No & No & No & No & No & Sí & No & No & No \\
\hline Efectos fijos & No & No & No & No & No & No & Sí & Sí & Sí \\
\hline Observaciones & 18.621 & 18.621 & 18.619 & 18.614 & 18.612 & 18.612 & 18.612 & 18.569 & 16.153 \\
\hline R-cuadrado & 0,024 & 0,038 & 0,065 & 0,009 & 0,069 & 0,081 & 0,034 & 0,036 & 0,051 \\
\hline
\end{tabular}

Nota: Errores estándar robustos entre paréntesis. ${ }^{* * *} \mathrm{p}<0,01,{ }^{* *} \mathrm{p}<0,05,{ }^{*} \mathrm{p}<0,1$. Resultados ajustados por factor de expansión.

Fuente: ENEMDU - Diciembre 2003-2014. 
A modo de conclusión, se puede recalcar que el bienestar global se relaciona negativamente con el nivel de aspiraciones económicas y con la percepción relativa de la pobreza. En el primer caso, un aumento del 10\% en las aspiraciones económicas mínimas, ceteris paribus, se relaciona con una disminución de 0,0234 puntos en la evaluación del bienestar global; mientras que en el segundo, el aumento de un punto en la percepción relativa de pobreza, ceteris paribus, se asocia con una disminución de - 0,127 puntos en el bienestar global. Adicionalmente, se puede destacar que los coeficientes del resto de variables incluidas de los modelos guardan consistencia con la evidencia empírica, al igual que en el caso del bienestar financiero.

\subsubsection{Contraste de resultados}

Al comparar los resultados de los modelos de bienestar financiero y global, se pudo determinar que la comparabilidad social o percepción relativa de la pobreza, es la única dimensión que afecta negativamente a ambas dimensiones. Este quiere decir que el bienestar de las personas tanto financiero como global es mayor para aquellas personas que perciben estar en un mejor estatus económico que el grupo de referencia con el cual se comparan. Sin embargo, si bien para el bienestar financiero resulta ser relevante el nivel de ingresos del hogar y la percepción absoluta de la pobreza, para el bienestar global resulta ser importante el nivel de aspiraciones económicas mínimas.

Estos resultados contrapuestos entre ambos modelos reflejan la existencia de ciertos mecanismos no necesariamente similares que actúan en ambas dimensiones. Por una parte, el hecho de que el bienestar financiero solo esté influido por el nivel de ingresos y por las percepciones de pobreza, implica que una persona evalúa su situación financiera en base a lo que tiene o percibe tener, y no según lo que desea tener.

Por su parte, el hecho de que el bienestar global no se relacione con el nivel de ingresos, es un resultado que va en contra de lo que generalmente suele hallarse cuando se analiza esta relación en un punto del tiempo. Esto se debe esencialmente a la inclusión de efectos fijos, destacando así la existencia de terceros factores que intervienen en la relación entre el bienestar global y el nivel de ingresos. De acuerdo a la literatura indagada, los factores más relevantes que se estarían controlando con la inclusión de efectos fijos y que intervienen en la relación bienestar-ingresos, tienen que ver con la personalidad del individuo, como su autoestima, proactividad, responsabilidad, etc. Estos factores, además de contribuir positivamente a la felicidad de las personas, pueden aportar positivamente a la consecución de metas educativas y profesionales. 
Otra diferencia entre ambos modelos sucede con las aspiraciones económicas: los hogares con una necesidad económica mayor presentan un menor nivel de bienestar global, pero no una menor satisfacción financiera.

\subsubsection{Análisis por quintiles de ingreso e influencia de las aspiraciones sobre el bienestar global}

Para analizar con mayor profundidad los resultados generales hasta acá mostrados, se realizó la estimación de los modelos en cada quintil de ingresos y para cada dimensión de bienestar disponible en la encuesta. El primer ejercicio se realiza con la finalidad de determinar si los resultados generales se dan a lo largo de la distribución de ingresos o si se concentran en una parte de ella, mientras que el segundo ejercicio tiene como finalidad ver los canales a través de los cuáles las aspiraciones económicas estarían afectando al bienestar global.

En las Tablas A.7 y A.8 se presentan las estimaciones del modelo de bienestar global y financiero para cada quintil de ingresos, considerando la especificación 8 de las Tablas 1 y 2. Al analizar las estimaciones para el bienestar financiero (Tabla A.7), se puede notar que las conclusiones previas de la influencia del nivel de ingresos y la percepción absoluta de la pobreza sobre esta dimensión, se dan a lo largo de la distribución, aunque en ciertos casos las relaciones no son estadísticamente significativas

A diferencia de esto, la percepción relativa de la pobreza resulta ser importante para el bienestar financiero, independientemente del nivel de ingresos. Esto pone en evidencia que las personas se sienten satisfechas con su situación financiera cuando perciben estar en un mejor estatus económico con respecto al grupo de referencia con el cual se comparan.

En el caso del bienestar global (Tabla A.8), al igual que el bienestar financiero, se distingue una asociación negativa y estadísticamente significativa con la percepción relativa de pobreza, a lo largo de la distribución. Sin embargo, también se puede destacar que esta relación se vuelve más negativa en los quintiles más altos de ingresos, lo que quiere decir que la comparabilidad social afecta más al bienestar de los hogares más ricos.

En cuanto a la relación entre el bienestar global y las aspiraciones económicas mínimas se puede notar que existe una relación negativa y estadísticamente significativa hasta el tercer quintil. Dado que en estos quintiles, la brecha entre el nivel de ingresos y las aspiraciones económicas es mayor (ver Figura 4), el hecho de no lograr alcanzar las 
aspiraciones económicas mínimas estaría afectando de algún modo al bienestar global.

Para tener un panorama más claro de por qué la imposibilidad de alcanzar los ingresos mínimos afecta negativamente al bienestar global, se realizó un ejercicio adicional $^{19}$. El formulario de la encuesta empleada pregunta a los encuestados acerca de su satisfacción con respecto a 14 dimensiones, la última de las cuales es justamente el bienestar general ${ }^{20}$. Dado que el bienestar general de cierto modo engloba las evaluaciones que dieron los individuos en las anteriores dimensiones, con esto se pretende determinar los canales a través de los que se da la relación negativa entre las aspiraciones económicas y el bienestar global. En la Tabla A.9 se puede notar que las aspiraciones económicas poseen una relación negativa y estadísticamente significativa con 7 de las 13 dimensiones, omitiendo el bienestar global. De estas, las que mayor magnitud presentan son: participación en la comunidad, vida social, familia y tiempo libre. Es decir, aquellas personas que poseen la mayor brecha entre ingresos y aspiraciones económicas mínimas, serían aquellas que tendrían un bajo nivel de satisfacción con el tiempo libre para pasar tiempo con su familia y de tener contacto social. Por lo tanto, se trataría de personas que se encuentran en una situación en la que deben trabajar el mayor tiempo posible para obtener un nivel de ingresos que no es suficiente como para cubrir sus gastos necesarios y que a la vez le impide contar con tiempo libre para realizar actividades que afectan positivamente al bienestar. A su vez, se puede tratar de personas que, en la búsqueda de un empleo, empiezan a tener una visión de túnel que les impide disfrutar de varios aspectos de la vida que son importantes para el bienestar. Posiblemente, el tiempo libre que poseen no es un espacio de distracción u ocio, sino un espacio en el que se preocupan por la condición económica del hogar.

\subsection{Análisis de robustez}

Con el fin de dar validez a las conclusiones halladas en el estudio, se realizaron dos análisis adicionales. En primer lugar, se consideraron las dos conclusiones distintas que arrojó el análisis de eventos, cuando se evaluó cómo afecta un cambio en el ingreso del hogar y un cambio en el ingreso laboral del jefe de hogar sobre el bienestar global. Si se compara la Figura 5b (ingreso per cápita del hogar) y Figura 7b (ingreso laboral del jefe

\footnotetext{
${ }^{19}$ Las conclusiones halladas acerca de la relación entre el bienestar global y las aspiraciones económicas se mantienen, si en el modelo se considera como variable explicativa a la brecha entre las aspiraciones económicas mínimas y el nivel de ingresos, en lugar de considerar a ambas variables por separado.

${ }^{20} \mathrm{El}$ bienestar global en este caso sigue un enfoque cognitivo, debido a que se le pide al individuo realizar una evaluación de su bienestar en general, considerando todos los aspectos de la vida.
} 
de hogar), se puede notar que un cambio en el decil de ingresos no produce un cambio en el bienestar distinto al resto de la población en el primer caso. No obstante, en el segundo caso, cuando el jefe de hogar experimenta un incremento del ingreso laboral, la variación del bienestar es positiva y estadísticamente diferente con respecto a quienes ven caer su ingreso laboral. Esto puede sugerir que la evaluación del bienestar del hogar estaría midiendo más bien el bienestar del jefe de hogar, debido a que es él quien realiza la evaluación del bienestar.

Para verificar que las conclusiones halladas en el presente trabajo no sean sensibles a los eventos que le ocurren al informante, se realizó una estimación de los modelos de bienestar financiero y global similares a los de la sección anterior, reemplazando en el conjunto de las variables explicativas al ingreso per cápita del hogar por el ingreso laboral del jefe de hogar. En las Tablas A.10 y A.11 se puede notar que los resultados son similares a los hallados en las secciones 4.4.1 y 4.4.2. Por lo tanto, las conclusiones dadas siguen siendo válidas y se descarta la posible influencia de eventos específicos que le ocurren al informante y que pueden afectar su evaluación del bienestar.

En segundo lugar, se estimaron los modelos de bienestar financiero y global considerando una métrica distinta para las variables dependientes. Los modelos hasta acá estimados incluyeron a la métrica del bienestar financiero y global en su escala original, es decir, como una escala discreta entre 1 y 10. Si bien, esta estrategia ha sido usada en otros estudios -suponiendo que las asociaciones son lineales a lo largo de la escala- se realizó una verificación de las conclusiones obtenidas incluyendo como variables dependientes a variables binarias de bienestar considerando distintos cortes para su construcción. En específico, las variables binarias se construyeron con distintos umbrales entre 5 y 8 con la finalidad de contar con una cantidad de observaciones adecuada entre categorías. En la Tabla A.12 se muestran las estimaciones de los modelos, pudiéndose notar que las conclusiones se mantienen.

\section{Conclusiones}

El presente trabajo tuvo como objetivo general analizar cómo el bienestar subjetivo financiero y global se relaciona con cuatro factores de interés: el ingreso, la percepción absoluta y relativa del nivel de pobreza, y las aspiraciones económicas. Si bien, existe una extensa literatura que analiza la relación entre el bienestar subjetivo y varios de estos factores, en el presente trabajo se aprovecha la disponibilidad de una estructura de datos de panel para aislar de mejor manera estas relaciones. 
Como análisis previo a la estimación de los modelos principales, se realizó un análisis de cómo el ingreso se relaciona con los factores de interés. Esto permitió determinar que hay una relación consistente entre el nivel de ingresos con las percepciones de pobreza y las aspiraciones económicas mínimas. Es decir, aquellas personas con mayores ingresos perciben ser menos pobres y estar en un estatus económico mejor que el resto; asimismo, se verificó que las aspiraciones económicas son crecientes en el ingreso, aunque la magnitud se reduce al controlar por otros factores.

Posteriormente, a pesar de que el panel solamente se compone de dos puntos en el tiempo con una longitud temporal de un año, se realizó un análisis de eventos para obtener un panorama preliminar de cómo se relaciona el bienestar con el ingreso, y otros eventos, cuando se analizan variaciones entre dos puntos del tiempo. Lo que se puede destacar es que, si bien, en un punto del tiempo hay una relación positiva entre el bienestar global y el ingreso, cuando se analiza la variación de estas dimensiones entre dos puntos de tiempo, no se encuentra una relación clara. A diferencia de esto, cuando una persona evalúa su situación financiera, esto si se relaciona con cambios en el ingreso.

Al realizar el análisis del bienestar global y financiero con los factores de interés, a través de una regresión de datos panel con la inclusión de efectos fijos y otras dimensiones que varían en el tiempo, se pudo determinar que la inclusión de efectos fijos fue lo más importante para aislar las relaciones de interés. Adicionalmente, una vez que se comprobó que las variables invariantes observables como el género, etnia y provincia no modifican las relaciones de interés, se puede destacar que los factores inobservables asociados a la personalidad de los individuos serían los que más influyen en la relación entre el bienestar y los factores de interés.

Al contrastar los resultados del bienestar global y financiero, se puede destacar que los cuatro factores analizados se asocian de manera distinta con estas dimensiones, a excepción de la percepción relativa de la pobreza, la cual se relaciona negativamente con ambos tipos de bienestar. Con respecto al resto de factores, el bienestar financiero muestra una relación con el nivel de ingresos y la percepción absoluta de pobreza, mientras que el bienestar global se relaciona solamente con las aspiraciones económicas mínimas. Esto quiere decir que si bien el bienestar financiero y global pueden depender de distintos factores, el hecho de que para ambos casos sea importante la dimensión de comparabilidad social muestra que sentirse en un mejor estatus económico que el grupo de referencia con el cual se compara la persona, es un aspecto altamente valorado tanto para sentirse bien en el ámbito financiero como en su vida en general.

Al realizar el análisis del bienestar financiero y global a lo largo de la distribución, se 
pudo determinar que la dimensión de comparabilidad social se relaciona negativamente con ambos tipos de bienestar, independientemente de la condición económica real del hogar. Además, en el caso del bienestar financiero, el resto de relaciones se mantienen a lo largo de la distribución; mientras que en el bienestar global, se encontró que las aspiraciones económicas mínimas presentan una relación negativa y estadísticamente significativa solamente en los tres primeros quintiles de ingreso, que son justamente los que poseen la brecha más amplia con respecto a las aspiraciones económicas mínimas.

$\mathrm{Al}$ analizar los posibles canales por los que las aspiraciones económicas mínimas estarían afectando al bienestar global, se pudo determinar que la imposibilidad de alcanzar las aspiraciones económicas mínimas se relaciona negativamente con la satisfacción en cuanto a la participación en la comunidad, vida social, familia y tiempo libre. Por lo tanto, se trataría de personas que destinan una buena parte de su tiempo al trabajo, el mismo que no les permite contar con los ingresos suficientes como para cubrir sus necesidades mínimas, y que les impide contar con tiempo libre para realizar actividades que aportan positivamente al bienestar, como la interacción social o pasar tiempo con la familia. Otra posible explicación tiene que ver con las restricciones cognitivas derivadas de la visión de túnel para aquellas personas que a pesar de contar con tiempo libre, no pueden usarlo para distraerse.

Si bien se suele sostener que un aumento en las características económicas objetivas como el ingreso permite aumentar el bienestar de los hogares más pobres, y que los mecanismos de comparación social son importantes a partir de que se supera cierto umbral de ingresos, los resultados hallados en el presente trabajo muestran varios matices. Por una parte, el ingreso se relaciona positivamente con el bienestar financiero, pero no muestra una relación con el bienestar global una vez que se controla por otros factores. Por otra parte, los mecanismos de comparación social inciden negativamente sobre ambos tipos de bienestar, independientemente del nivel de ingresos de las personas. Este contraste de resultados obedece principalmente a la capacidad de controlar por efectos fijos, destacando sobre todo la importancia de factores inobservables relacionados a la personalidad de los individuos.

Finalmente, no se puede descartar que la inexistencia de una relación entre el bienestar global y el nivel de ingresos pueda estar asociado a un mecanismo de adaptación, en la que el hogar pudo haber experimentado un aumento del bienestar que se fue disipando a lo largo del periodo de análisis; sin embargo, esta hipótesis no puede ser analizada en profundidad debido a la longitud temporal del panel. Asimismo, la ausencia de una relación entre el bienestar global y el nivel de ingresos podría deberse a la naturaleza 
volátil de este último, ya que para el hogar puede no ser suficiente un aumento esporádico del nivel de ingresos si sabe que después de un tiempo puede regresar a los niveles anteriores; en este sentido, la disponibilidad de información sobre el consumo o riqueza podrían ser útiles para evaluar esta hipótesis. 


\section{Referencias}

Alem, Y. y Colmer, J. (2015). Consumption smoothing and the welfare cost of uncertainty. CEP Discussion Papers, CEPDP1369, Centre for Economic Performance, London School of Economics and Political Science, London, UK.

Alesina, A., Tella, R. D., y MacCulloch, R. (2004). Inequality and happiness: are europeans and americans different? Journal of Public Economics, 88(9-10):20092042.

Anderson, C., Kraus, M. W., Galinsky, A. D., y Keltner, D. (2012). The local-ladder effect: Social status and subjective well-being. Psychological Science, 23(7):764-771.

Brickman, P. y Campbell, D. T. (1971). Hedonic relativism and planning the good society, pp. 287-305. Adaptation-level theory. New York: Academic Press.

Brockmann, H., Delhey, J., Welzel, C., y Yuan, H. (2008). The china puzzle: Falling happiness in a rising economy. Journal of Happiness Studies, 10(4):387-405.

Cancho, C., Davalos, M. E., Demarchi, G., Meyer, M., y Paramo, C. S. (2015). Economic mobility in europe and central asia : exploring patterns and uncovering puzzles. Policy Research working paper ; no. WPS 7173, Washington, DC: World Bank Group.

Castillo, R. (2015). Empleo y condición de actividad en ecuador. Nota técnica, Coordinación General Técnica de Innovación en Métricas y Análisis de la Información, INEC.

Clark, A. E., Frijters, P., y Shields, M. A. (2008). Relative income, happiness, and utility: An explanation for the easterlin paradox and other puzzles. Journal of Economic Literature, 46(1):95-144.

Clark, A. E. y Oswald, A. J. (1996). Satisfaction and comparison income. Journal of Public Economics, 61(3):359-381.

Corazzini, L., Esposito, L., y Majorano, F. (2011). Exploring the absolutist vs relativist perception of poverty using a cross-country questionnaire survey. Journal of Economic Psychology, 32(2):273-283.

Cummins, R. A. (2000). Personal income and subjective well-being: A review. Journal of Happiness Studies, 1(2):133-158. 
Dang, H.-A. H. e Ianchovichina, E. (2016). Welfare dynamics with synthetic panels: The case of the arab world in transition. World Bank, Policy Research Working Paper, No. 7595 .

Di Tella, R., MacCulloch, R. J., y Oswald, A. J. (2001). Preferences over inflation and unemployment: Evidence from surveys of happiness. American Economic Review, 91(1):335-341.

Diener, E. (1984). Subjective well-being. Psychological Bulletin, 95(3).

Diener, E. (2000). Subjective well-being: The science of happiness and a proposal for a national index. American Psychologist, 55(1):34-43.

Diener, E. (2009). The Science of Well-Being. Social Indicators Research Series. Springer.

Diener, E. y Biswas-Diener, R. (2002). Will money increase subjective well-being?: A literature review and guide to needed research. Social Indicators Research, 57(2):119 169.

Diener, E., Lucas, R. E., Oishi, S., y Suh, E. M. (2002). Looking up and looking down: Weighting good and bad information in life satisfaction judgments. Personality and Social Psychology Bulletin, 28(4):437-445.

Diener, E., Sandvik, E., Seidlitz, L., y Diener, M. (1993). The relationship between income and subjective well-being: Relative or absolute? Social Indicators Research, 28(3):195-223.

Diener, E. y Seligman, M. E. (2004). Beyond money. Psychological Science in the Public Interest, 5(1):1-31.

Diener, E., Suh, E. M., Lucas, R. E., y Smith, H. L. (1999). Subjective well-being: Three decades of progress. Psychological Bulletin, 29:94-122.

Dolan, P., Peasgood, T., y White, M. (2008). Do we really know what makes us happy? a review of the economic literature on the factors associated with subjective well-being. Journal of Economic Psychology, 29(1):94-122.

Easterlin, R. (1974). Does Economic Growth Improve the Human Lot? Nations and Households in Economic Growth: Essays in Honour of Moses Abramovitz. New York: Academic Press, Inc. 
Easterlin, R. A. (1995). Will raising the incomes of all increase the happiness of all? Journal of Economic Behavior \& Organization, 27(1):35-47.

Gasparini, L. (2010). Happiness and development policy. comment to "happiness measures as a guide to development policy?" by carol graham. Annual Bank Conference on Development Economics (ABCDE). Stockholm.

Graham, C. (2009). Happiness Around the World: The Paradox of Happy Peasants and Miserable Millionaires. Oxford.

Graham, C. y Pettinato, S. (2002). Frustrated achievers: Winners, losers and subjective well-being in new market economies. Journal of Development Studies, 38(4):100-140.

Hadjar, A. y Samuel, R. (2015). Does upward social mobility increase life satisfaction? a longitudinal analysis using british and swiss panel data. Research in Social Stratification and Mobility, 39:48-58.

Hirsch, F. (1976). Social Limits to Growth. Routledge \& Kegan Paul Ltd.

Houle, J. N. y Martin, M. A. (2011). Does intergenerational mobility shape psychological distress? sorokin revisited. Research in Social Stratification and Mobility, 29(2):193203.

INEC (2017). Enemdu: Indicadores laborales de junio 2017. Technical report.

Inglehart, R. (2000). Globalization and postmodern values. The Washington Quarterly, $23(1): 215-228$.

Kahneman, D. (2011). Pensar Rápido, Pensar Despacio. Barcelona, España: Farrar, Stratus and Giroux.

Kahneman, D. y Deaton, A. (2010). High income improves evaluation of life but not emotional well-being. Proceedings of the National Academy of Sciences, 107(38):1648916493.

Knight, J. y Gunatilaka, R. (2012). Income, aspirations and the hedonic treadmill in a poor society. Journal of Economic Behavior \& Organization, 82(1):67-81.

Kruger, P. S. y Engelbrecht, S. W. P. (2010). Happiness around the world the paradox of happy peasants and miserable millionaires. Applied Research in Quality of Life, $5(3): 165-169$. 
Li, Y. (2016). Social mobility, social network and subjective well-being in the UK. Contemporary Social Science, 11(2-3):222-237.

Li, Y., Savage, M., y Pickles, A. (2003). Social capital and social exclusion in england and wales (1972-1999). The British Journal of Sociology, 54(4):497-526.

Liang, J., Kahana, E., y Doherty, E. (1980). Financial weil-being among the aged: A further elaboration. Journal of Gerontology, 35(3):409-420.

Lucas, R. y Diener, E. (2008). Subjective Well-Being, pp. 471-484. Handbook of Emotions, Third Edition. New York: Guilford Press.

Molnar, G. y Kapitány, Z. (2006). Mobility, uncertainty and subjective well-being in hungary. Institute of Economics, Centre for Economic and Regional Studies, Hungarian Academy of Sciences.

Nikolaev, B. y Burns, A. (2014). Intergenerational mobility and subjective wellbeing - evidence from the general social survey. Journal of Behavioral and Experimental Economics, 53:82-96.

Putman, R. (2000). Bowling Alone: The Collapse and Revival of American Community. Simon \& Schuster.

Ravallion, M. (2014). Poor, or just feeling poor? on using subjective data in measuring poverty. En Happiness and Economic Growth, pp. 140-178. Oxford University Press.

Ravallion, M. y Lokshin, M. (2010). Who cares about relative deprivation? Journal of Economic Behavior \& Organization, 73(2):171-185.

Shin, D. C. y Johnson, D. M. (1978). Avowed happiness as an overall assessment of the quality of life. Social Indicators Research, 5(1-4):475-492.

Stutzer, A. (2004). The role of income aspirations in individual happiness. Journal of Economic Behavior \&S Organization, 54(1):89-109.

Suh, E., Diener, E., y Fujita, F. (1996). Events and subjective well-being: Only recent events matter. Journal of Personality and Social Psychology, 70(5):1091-1102.

Tov, W. y Diener, E. (2009). The well-being of nations: Linking together trust, cooperation, and democracy. En Social Indicators Research Series, pp. 155-173. Springer Netherlands. 
Wilkinson, R. y Pickett, K. (2009). The Spirit Level: Why Greater Equality Makes Societies Stronger. New York: Bloomsbury Press.

Wolfers, J. (2003). Is business cycle volatility costly? evidence from surveys of subjective well-being. International Finance, 6(1):1-26.

Zang, E. y de Graaf, N. D. (2016). Frustrated achievers or satisfied losers? inter- and intragenerational social mobility and happiness in china. Sociological Science, 3:779800 . 


\section{A. Anexos}

\section{A.1. Estadísticos descriptivos y análisis complementarios.}

Tabla A.1: Estadísticos descriptivos de los hogares 2013-2014.

a) Variables continuas

\begin{tabular}{lrrrrr}
\hline VARIABLE & Año & Media & $\begin{array}{l}\text { Desvío } \\
\text { estándar }\end{array}$ & Mínimo & Máximo \\
\hline Edad & 2013 & 52,1 & 15,6 & 16 & 98 \\
& 2014 & 53,1 & 15,6 & 17 & 98 \\
Sexo (1=Hombres) & 2013 & 0,74 & 0,44 & 0 & 1 \\
& 2014 & 0,74 & 0,44 & 0 & 1 \\
Tamaño de hogar & 2013 & 4,0 & 2,0 & 1 & 18 \\
& 2014 & 3,9 & 2,0 & 1 & 18 \\
\hline
\end{tabular}

b) Variables categóricas

\begin{tabular}{llrr}
\hline VARIABLE & & $\mathbf{2 0 1 3}$ & $\mathbf{2 0 1 4}$ \\
\hline \multirow{2}{*}{ Estado civil } & Unido & $68,1 \%$ & $66,5 \%$ \\
\multirow{2}{*}{ Nivel de instrucción } & $31,9 \%$ & $33,5 \%$ \\
& Solo & $6,4 \%$ & $5,7 \%$ \\
& Ninguno & $49,5 \%$ & $49,2 \%$ \\
& Primaria & $28,1 \%$ & $28,9 \%$ \\
& Secundaria & $16,0 \%$ & $16,1 \%$ \\
Etnia & Superior & $84,3 \%$ & $85,4 \%$ \\
\multirow{2}{*}{ Condición de actividad } & Mestizo & $15,7 \%$ & $14,6 \%$ \\
& Minoría & $38,3 \%$ & $42,3 \%$ \\
& Inadecuado & $41,4 \%$ & $37,9 \%$ \\
& Desempleo & $1,3 \%$ & $1,3 \%$ \\
No. Hogares & Inactivo & $19,0 \%$ & $18,5 \%$ \\
& & 4.281 .020 & 4.281 .020 \\
\hline
\end{tabular}

Nota: El ingreso se expresa en dólares de 2013. Se pondera por factores de expansión. Los estadísticos calculados corresponden al jefe de hogar.

Fuente: ENEMDU - Diciembre 2003-2014. 
Tabla A.2: Estadísticos del ingreso per cápita del hogar.

\begin{tabular}{|c|c|c|}
\hline & 2013 & 2014 \\
\hline Media & 198,8 & 220,9 \\
\hline \multicolumn{3}{|l|}{ Percentiles } \\
\hline $1 \%$ & 18,8 & 20,9 \\
\hline $5 \%$ & 38,6 & 42,2 \\
\hline $10 \%$ & 50,6 & 57,8 \\
\hline $50 \%$ & 135,3 & 154,2 \\
\hline $75 \%$ & 240,9 & 266,0 \\
\hline $90 \%$ & 386,5 & 439,5 \\
\hline $95 \%$ & 549,3 & 602,4 \\
\hline $99 \%$ & 1036,1 & 1156,5 \\
\hline Mínimo & 1,6 & 2,4 \\
\hline Máximo & 4818,8 & 4192,4 \\
\hline Desvío estándar & 220,8 & 233,3 \\
\hline Coeficiente de variación & 1,11 & 1,06 \\
\hline Gini & 0,453 & 0,444 \\
\hline \multicolumn{3}{|l|}{ Participación } \\
\hline Decil1 & $2,2 \%$ & $2,5 \%$ \\
\hline Decil2 & $3,3 \%$ & $3,3 \%$ \\
\hline Decil3 & $4,2 \%$ & $4,7 \%$ \\
\hline Decil4 & $5,3 \%$ & $4,9 \%$ \\
\hline Decil5 & $6,2 \%$ & $6,5 \%$ \\
\hline Decil6 & $7,3 \%$ & $7,0 \%$ \\
\hline Decil7 & $8,5 \%$ & $8,5 \%$ \\
\hline Decil8 & $11,2 \%$ & $11,0 \%$ \\
\hline Decil9 & $14,6 \%$ & $15,0 \%$ \\
\hline Decil10 & $31,9 \%$ & $30,4 \%$ \\
\hline No. Hogares & 4.281 .020 & 4.281 .020 \\
\hline
\end{tabular}

Nota: El ingreso se expresa en dólares de 2013. Se pondera por factores de expansión.

Fuente: ENEMDU - Diciembre 2003-2014.

Tabla A.3: Transiciones entre quintiles de ingreso per cápita del hogar.

\begin{tabular}{crrrrrr}
\hline & \multicolumn{7}{c}{ Quintil 2014 } & & \multicolumn{1}{c}{ Total } \\
\hline $\mathbf{1}$ & & $\mathbf{2}$ & $\mathbf{3}$ & $\mathbf{4}$ & $\mathbf{5}$ & \\
& 439.381 & 213.570 & 130.042 & 56.453 & 17.136 & 856.582 \\
$\mathbf{2}$ & 51,3 & 24,9 & 15,2 & 6,6 & 2,0 & 100,0 \\
& 219.979 & 306.194 & 190.165 & 113.496 & 32.589 & 862.424 \\
$\mathbf{3}$ & 25,5 & 35,5 & 22,1 & 13,2 & 3,8 & 100,0 \\
& 125.385 & 191.469 & 264.614 & 197.411 & 71.061 & 849.940 \\
$\mathbf{4}$ & 14,8 & 22,5 & 31,1 & 23,2 & 8,4 & 100,0 \\
& 54.683 & 110.563 & 197.268 & 303.913 & 189.49 & 855.917 \\
$\mathbf{5}$ & 6,4 & 12,9 & 23,1 & 35,5 & 22,1 & 100,0 \\
& 18.252 & 39.917 & 67.627 & 187.544 & 542.816 & 856.156 \\
Total & 2,1 & 4,7 & 7,9 & 21,9 & 63,4 & 100,0 \\
& 857.681 & 861.714 & 849.716 & 858.816 & 853.092 & 4.281 .020 \\
& 20,0 & 20,1 & 19,9 & 20,1 & 19,9 & 100,0 \\
\hline
\end{tabular}

Nota: Se pondera por factores de expansión.

Fuente: ENEMDU - Diciembre 2003-2014. 
Tabla A.4: Regresiones de las dimensiones subjetivas sobre el ingreso per cápita familiar.

\begin{tabular}{lcccc}
\hline Dimensión & Coeficiente & Error estándar & $\mathbf{N}$ & R-cuadrado \\
\hline Profesión & $0,680^{* * *}$ & $(0,0256)$ & 15.518 & 0,062 \\
Trabajo & $0,647^{* * *}$ & $(0,0245)$ & 15.915 & 0,062 \\
Situación financiera & $0,838^{* * *}$ & $(0,0210)$ & 18.612 & 0,113 \\
Estado de salud & $0,430^{* * *}$ & $(0,0216)$ & 18.608 & 0,032 \\
Vivienda & $0,602^{* * *}$ & $(0,0219)$ & 18.614 & 0,055 \\
Tiempo libre & $0,334^{* * *}$ & $(0,0209)$ & 18.611 & 0,021 \\
Familia & $0,180^{* * *}$ & $(0,0179)$ & 18.619 & 0,007 \\
Educación & $0,718^{* * *}$ & $(0,0232)$ & 18.610 & 0,068 \\
Medio ambiente & $0,181^{* * *}$ & $(0,0202)$ & 18.618 & 0,007 \\
Vida social & $0,271^{* * *}$ & $(0,0203)$ & 18.604 & 0,015 \\
Estado civil & $0,223^{* * *}$ & $(0,0220)$ & 18.616 & 0,008 \\
Participación en la comunidad & $0,111^{* * *}$ & $(0,0224)$ & 18.621 & 0,003 \\
Gobierno & $0,128^{* * *}$ & $(0,0234)$ & 18.610 & 0,032 \\
Bienestar global & $0,264^{* * *}$ & $(0,0161)$ & 18.621 & 0,024 \\
\hline
\end{tabular}

Nota: Se estima una regresión de cada dimensión de bienestar sobre el ingreso per cápita del hogar y una dummy de año. Errores estándar robustos entre paréntesis. ${ }^{* * *} \mathrm{p}<0,01,{ }^{* *} \mathrm{p}<0,05$, $* \mathrm{p}<0,1$. Resultados ajustados por factor de expansión.

Fuente: ENEMDU - Diciembre 2003-2014. 


\section{A.2. Casos especiales de estudios de eventos.}

Figura A.1: Cambio en el bienestar según cambio en deciles del ingreso de miembros secundarios.

(a) Bienestar financiero

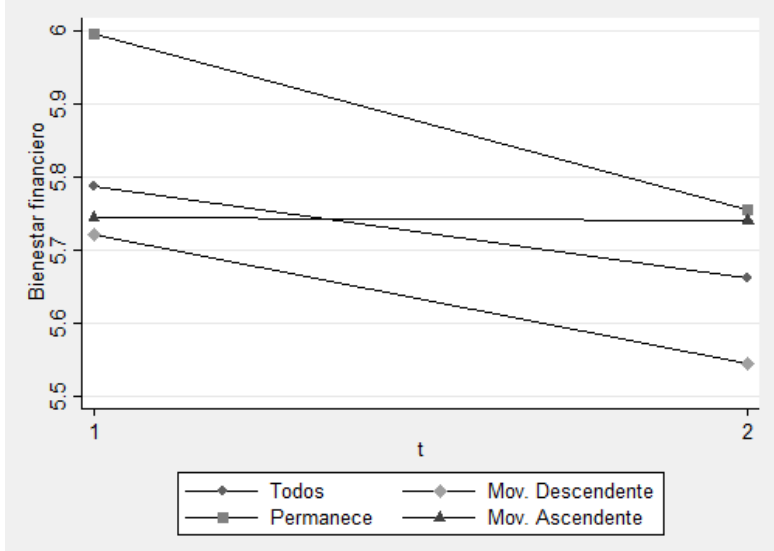

(b) Bienestar global

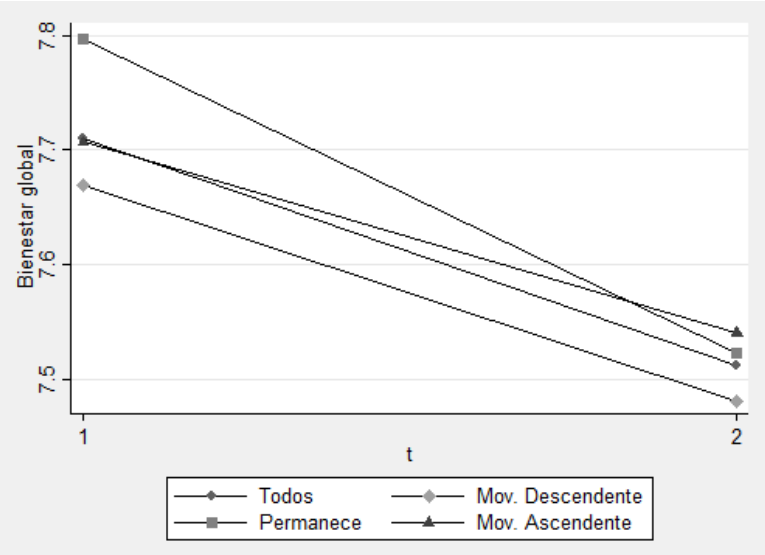

Nota: Se descartan los hogares que no disponen de un ingreso adicional al del jefe de hogar en ambos periodos.

Fuente: ENEMDU - Diciembre 2013-2014.

Figura A.2: Cambio en el bienestar según cambio en deciles del ingreso de las mujeres.

(a) Bienestar financiero

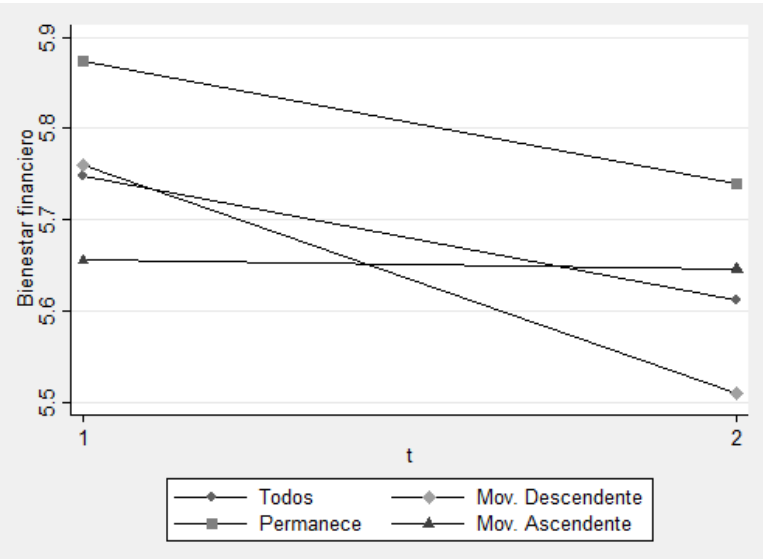

(b) Bienestar global

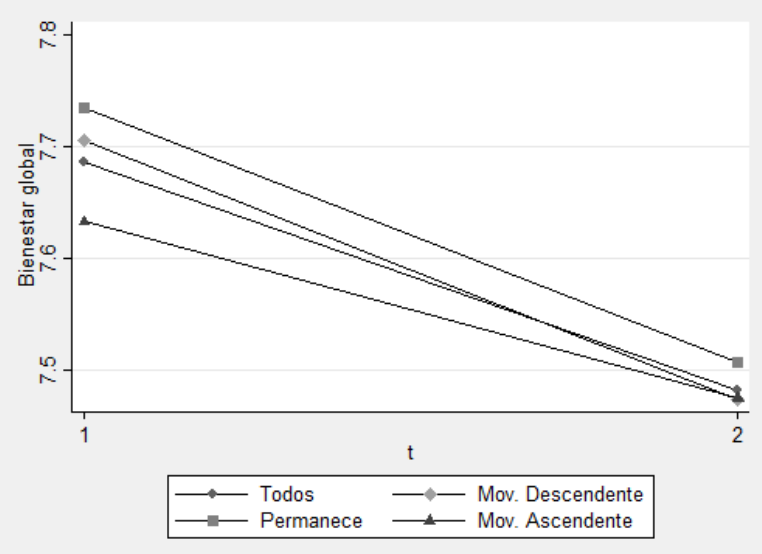

Nota: Se descartan los hogares que no poseen ingresos de mujeres en ambos periodos.

Fuente: ENEMDU - Diciembre 2013-2014. 


\section{A.3. Modelos complementarios.}

Tabla A.5: Determinantes del nivel de aspiraciones.

\begin{tabular}{|c|c|c|c|c|c|c|}
\hline VARIABLES & (1) & $(2)$ & (3) & $(4)$ & (5) & $(6)$ \\
\hline Logaritmo ingreso & $\begin{array}{l}0,569 * * * \\
(0,00716)\end{array}$ & & & $\begin{array}{l}0,545^{* * *} \\
(0,00819)\end{array}$ & $\begin{array}{l}0,501^{* * *} \\
(0,00910)\end{array}$ & $\begin{array}{l}0,274^{* * *} \\
(0,0154)\end{array}$ \\
\hline $\begin{array}{l}\text { Considera_pobre (ab- } \\
\text { soluto) }\end{array}$ & & $-0,473^{* * *}$ & & $-0,0497^{* * *}$ & $-0,0109$ & 0,00130 \\
\hline $\begin{array}{l}\text { Considera_pobre (rela- } \\
\text { tivo) }\end{array}$ & & $(0,0146)$ & $-0,135^{* * *}$ & $\begin{array}{l}(0,0149) \\
-0,0138^{* * *}\end{array}$ & $\begin{array}{l}(0,0147) \\
-0,00158\end{array}$ & $\begin{array}{r}(0,0198) \\
-0,00453\end{array}$ \\
\hline $\begin{array}{l}\text { Condición de actividad } \\
\text { (Ref: Adecuado) }\end{array}$ & & & $(0,00390)$ & $(0,00416)$ & $(0,00419)$ & $(0,00533)$ \\
\hline Inadecuado/Desempleado & & & & & $\begin{array}{l}0,0260^{*} \\
(0,0133)\end{array}$ & $\begin{array}{l}-0,0243 \\
(0,0207)\end{array}$ \\
\hline Inactivo & & & & & $\begin{array}{l}0,0576^{* * *} \\
(0,0183)\end{array}$ & $\begin{array}{l}-0,0322 \\
(0,0303)\end{array}$ \\
\hline $\begin{array}{l}\text { Nivel de instrucción } \\
\text { (Ref: Ninguna) }\end{array}$ & & & & & & \\
\hline Primaria & & & & & $\begin{array}{l}0,0815^{* * *} \\
(0,0211)\end{array}$ & $\begin{array}{l}0,0114 \\
(0,0489)\end{array}$ \\
\hline Secundaria & & & & & $\begin{array}{l}0,252^{* * *} \\
(0,0239)\end{array}$ & $\begin{array}{c}-0,00892 \\
(0,0566)\end{array}$ \\
\hline Superior & & & & & $\begin{array}{l}0,419^{* * *} \\
(0,0276)\end{array}$ & $\begin{array}{l}0,0322 \\
(0,0733)\end{array}$ \\
\hline Edad & & & & & $\begin{array}{l}0,000949 \\
(0,00205)\end{array}$ & $\begin{array}{l}0,0255 \\
(0,0194)\end{array}$ \\
\hline $\operatorname{Edad}^{2}$ & & & & & $\begin{array}{l}2,04 \mathrm{e}-05 \\
(1,90 \mathrm{e}-05)\end{array}$ & $\begin{array}{l}-0,000252^{*} \\
(0,000151)\end{array}$ \\
\hline 2014 & $\begin{array}{l}0,0140 \\
(0,0106)\end{array}$ & $\begin{array}{l}0,0670^{* * *} \\
(0,0132)\end{array}$ & $\begin{array}{l}0,0925^{* * *} \\
(0,0131)\end{array}$ & $\begin{array}{l}0,0163 \\
(0,0106)\end{array}$ & $\begin{array}{l}0,0177^{*} \\
(0,0105)\end{array}$ & $\begin{array}{l}0,0496^{* * *} \\
(0,0104)\end{array}$ \\
\hline Constante & $\begin{array}{l}2,397^{* * *} \\
(0,0355)\end{array}$ & $\begin{array}{l}5,526^{* * *} \\
(0,0142)\end{array}$ & $\begin{array}{l}5,971^{* * *} \\
(0,0250)\end{array}$ & $\begin{array}{l}2,627^{* * *} \\
(0,0528)\end{array}$ & $\begin{array}{l}2,444^{* * *} \\
(0,0769)\end{array}$ & $\begin{array}{l}3,306^{* * *} \\
(0,606)\end{array}$ \\
\hline Efectos fijos & No & No & No & No & No & Sí \\
\hline Observaciones & 18.620 & 18.620 & 18.618 & 18.618 & 18.618 & 18.618 \\
\hline R-cuadrado & 0,409 & 0,095 & 0,102 & 0,411 & 0,434 & 0,092 \\
\hline
\end{tabular}

Nota: Errores estándar robustos entre paréntesis. ${ }^{* * *} \mathrm{p}<0,01,{ }^{* *} \mathrm{p}<0,05,{ }^{*} \mathrm{p}<0,1$. Resultados ajustados por factor de expansión.

Fuente: ENEMDU - Diciembre 2003-2014. 
Tabla A.6: Regresiones de los análisis de eventos.

\begin{tabular}{lcc}
\hline & Bienestar financiero & Bienestar global \\
\hline I) Ingreso per cápita del hogar (Ref: & Permanece) & \\
\hline Descendente & $-0,130^{*}$ & 0,0330 \\
& $(0,0680)$ & $(0,0560)$ \\
Ascendente & $0,334^{* * *}$ & 0,0369 \\
& $(0,0684)$ & $(0,0564)$ \\
\hline Observaciones & 9.296 & 9.305 \\
R-cuadrado & 0,006 & 0,000 \\
\hline
\end{tabular}

II) Ingreso per cápita del hogar (deciles altos y bajos) (Ref: Descendente $(<=5)$

\begin{tabular}{lcc}
\hline Permanece decil bajo $(<=5)$ & 0,0959 & $-0,0191$ \\
& $(0,0942)$ & $(0,0778)$ \\
Permanece decil alto $(>5)$ & $0,156^{*}$ & $-0,105$ \\
& $(0,0871)$ & $(0,0719)$ \\
Ascendente $(>5)$ & $0,536^{* * *}$ & $-0,0209$ \\
& $(0,0748)$ & $(0,0618)$ \\
\hline Observaciones & 7.003 & 7.010 \\
R-cuadrado & 0,008 & 0,000 \\
\hline
\end{tabular}

\begin{tabular}{lcc}
\hline III) Ingreso laboral del jefe de hogar (Ref: Permanece) & \\
\hline Descendente & $-0,389^{* * *}$ & $-0,0116$ \\
& $(0,0753)$ & $(0,0620)$ \\
Ascendente & $0,132^{*}$ & 0,0933 \\
& $(0,0749)$ & $(0,0616)$ \\
\hline Observaciones & 8.060 & 8.066 \\
R-cuadrado & 0,008 & 0,001 \\
\hline
\end{tabular}

\begin{tabular}{lcc}
\hline IV) Condición de actividad del jefe de hogar & Ref: Pierde empleo) \\
\hline Encuentra empleo & $0,604^{* * *}$ & $0,213^{* *}$ \\
& $(0,101)$ & $(0,0834)$ \\
Sigue con empleo & $0,279^{* * *}$ & 0,0958 \\
& $(0,0741)$ & $(0,0611)$ \\
Sigue sin empleo & $0,134^{*}$ & 0,0983 \\
& $(0,0777)$ & $(0,0640)$ \\
\hline Observaciones & 8.186 & 8.193 \\
R-cuadrado & 0,005 & 0,001 \\
\hline
\end{tabular}

V) Ingreso per cápita del hogar (deciles medios) (Ref: Descendente)

\begin{tabular}{lcc}
\hline Permanece decil bajo $(<=5)$ & 0,0963 & 0,0148 \\
& $(0,0900)$ & $(0,0742)$ \\
Permanece decil alto $(>5)$ & $0,157^{*}$ & $-0,0707$ \\
& $(0,0826)$ & $(0,0680)$ \\
Ascendente & $0,463^{* * *}$ & 0,00387 \\
& $(0,0613)$ & $(0,0506)$ \\
\hline Observaciones & 9.296 & 9.305 \\
R-cuadrado & 0,006 & 0,000 \\
\hline
\end{tabular}

continúa... 


\begin{tabular}{|c|c|c|}
\hline & Bienestar financiero & Bienestar global \\
\hline \multicolumn{3}{|c|}{ VI) Ingreso de miembros secundarios (Ref: Permanece) } \\
\hline Descendente & $\begin{array}{c}0,0641 \\
(0,0820)\end{array}$ & $\begin{array}{c}0,0859 \\
(0,0668)\end{array}$ \\
\hline Ascendente & $\begin{array}{c}0,230^{* * *} \\
(0,0830)\end{array}$ & $\begin{array}{c}0,106 \\
(0,0676)\end{array}$ \\
\hline Observaciones & 7.210 & 7.218 \\
\hline R-cuadrado & 0,001 & 0,000 \\
\hline \multicolumn{3}{|c|}{ VII) Ingreso de mujeres (Ref: Permanece) } \\
\hline Descendente & $\begin{array}{c}-0,113 \\
(0,0770)\end{array}$ & $\begin{array}{r}-0,00631 \\
(0,0633)\end{array}$ \\
\hline Ascendente & $\begin{array}{c}0,117 \\
(0,0786)\end{array}$ & $\begin{array}{c}0,0609 \\
(0,0647)\end{array}$ \\
\hline Observaciones & 7.501 & 7.506 \\
\hline R-cuadrado & 0,002 & 0,000 \\
\hline
\end{tabular}

Nota: Errores estándar robustos entre paréntesis. ${ }^{* * *} \mathrm{p}<0,01,{ }^{* *} \mathrm{p}<0,05,{ }^{*} \mathrm{p}<0,1$. Resultados ajustados por factor de expansión. Todas las regresiones incluyen una constante.

Fuente: ENEMDU - Diciembre 2003-2014. 
Tabla A.7: Modelo de bienestar financiero por quintiles de ingreso.

\begin{tabular}{|c|c|c|c|c|c|}
\hline VARIABLES & (1) & $(2)$ & (3) & (4) & (5) \\
\hline Logaritmo ingreso & $\begin{array}{l}0,0403 \\
(0,0953)\end{array}$ & $\begin{array}{l}0,267^{* *} \\
(0,119)\end{array}$ & $\begin{array}{l}0,186 \\
(0,125)\end{array}$ & $\begin{array}{l}0,295 * * \\
(0,135)\end{array}$ & $\begin{array}{l}0,520^{* * *} \\
(0,126)\end{array}$ \\
\hline \multirow{2}{*}{$\begin{array}{l}\text { Considera_pobre } \\
\text { (absoluto) }\end{array}$} & $-0,580 * * *$ & $-0,195$ & $-0,177$ & $-0,0384$ & $-0,300^{* *}$ \\
\hline & $(0,183)$ & $(0,150)$ & $(0,157)$ & $(0,152)$ & $(0,138)$ \\
\hline \multirow{2}{*}{$\begin{array}{l}\text { Considera_pobre } \\
\text { (relativo) }\end{array}$} & $-0,349 * * *$ & $-0,418^{* * *}$ & $-0,363^{* * *}$ & $-0,309^{* * *}$ & $-0,310^{* * *}$ \\
\hline & $(0,0382)$ & $(0,0388)$ & $(0,0441)$ & $(0,0497)$ & $(0,0411)$ \\
\hline \multirow{3}{*}{$\begin{array}{l}\text { Logaritmo } \\
\text { aspiraciones } \\
\text { Condición de actividad } \\
\text { (Ref: Adecuado) }\end{array}$} & $-0,101$ & $-0,157$ & $-0,0191$ & 0,0569 & 0,145 \\
\hline & $(0,111)$ & $(0,118)$ & $(0,124)$ & $(0,132)$ & $(0,109)$ \\
\hline & & & & & \\
\hline \multirow{2}{*}{$\begin{array}{l}\text { Inadecuado/ } \\
\text { Desempleado }\end{array}$} & $-0,0156$ & $-0,0676$ & $-0,397^{* *}$ & $-0,337 * *$ & $-0,0308$ \\
\hline & $(0,179)$ & $(0,156)$ & $(0,179)$ & $(0,162)$ & $(0,181)$ \\
\hline \multirow[t]{2}{*}{ Inactivo } & $-0,536^{* *}$ & $-0,249$ & $-0,175$ & $-0,0499$ & 0,0798 \\
\hline & $(0,265)$ & $(0,249)$ & $(0,270)$ & $(0,278)$ & $(0,273)$ \\
\hline \multicolumn{6}{|l|}{$\begin{array}{l}\text { Nivel de instrucción } \\
\text { (Ref: Ninguna) }\end{array}$} \\
\hline \multirow[t]{2}{*}{ Primaria } & 0,285 & 0,0482 & $-0,198$ & 0,520 & $-0,656$ \\
\hline & $(0,303)$ & $(0,252)$ & $(0,299)$ & $(0,348)$ & $(0,612)$ \\
\hline \multirow[t]{2}{*}{ Secundaria } & $0,646^{*}$ & $-0,112$ & $-0,0870$ & 0,585 & $-0,829$ \\
\hline & $(0,370)$ & $(0,338)$ & $(0,384)$ & $(0,422)$ & $(0,684)$ \\
\hline \multirow[t]{2}{*}{ Superior } & 1,099 & 0,689 & 0,0193 & 0,503 & $-0,951$ \\
\hline & $(0,683)$ & $(0,610)$ & $(0,604)$ & $(0,547)$ & $(0,728)$ \\
\hline \multicolumn{6}{|l|}{ Estado civil (Ref: } \\
\hline \multicolumn{6}{|l|}{ Casado/Unido) } \\
\hline \multirow[t]{2}{*}{ Soltero/Solo } & 0,117 & 0,342 & $-0,0664$ & $-0,487$ & 0,173 \\
\hline & $(0,336)$ & $(0,313)$ & $(0,257)$ & $(0,299)$ & $(0,249)$ \\
\hline \multirow[t]{2}{*}{ Edad } & 0,157 & $-0,0689$ & 0,00638 & $-0,101$ & $-0,123$ \\
\hline & $(0,115)$ & $(0,118)$ & $(0,125)$ & $(0,147)$ & $(0,145)$ \\
\hline \multirow[t]{2}{*}{$\operatorname{Edad}^{2}$} & $-0,00153$ & 0,000968 & 0,000657 & 0,000269 & 0,000689 \\
\hline & $(0,000940)$ & $(0,000910)$ & $(0,00103)$ & $(0,00121)$ & $(0,00122)$ \\
\hline \multirow[t]{2}{*}{ Tamaño del hogar } & $-0,0271$ & 0,0768 & 0,00162 & 0,0596 & $0,169^{* * *}$ \\
\hline & $(0,0452)$ & $(0,0603)$ & $(0,0615)$ & $(0,0665)$ & $(0,0629)$ \\
\hline \multirow[t]{2}{*}{ Práctica de deporte } & $0,258^{*}$ & $-0,312^{* *}$ & $-0,0107$ & $0,238^{*}$ & 0,187 \\
\hline & $(0,140)$ & $(0,153)$ & $(0,156)$ & $(0,143)$ & $(0,126)$ \\
\hline \multirow[t]{2}{*}{ Año 2014} & $-0,225^{* * *}$ & $-0,197^{* *}$ & $-0,252^{* * *}$ & $-0,133$ & $-0,116$ \\
\hline & $(0,0823)$ & $(0,0812)$ & $(0,0862)$ & $(0,0983)$ & $(0,0970)$ \\
\hline \multirow[t]{2}{*}{ Constante } & 4,285 & $8,104^{* *}$ & 5,222 & $9,907 * *$ & $9,037 * *$ \\
\hline & $(3,403)$ & $(3,810)$ & $(3,852)$ & $(4,444)$ & $(4,358)$ \\
\hline Efectos fijos & Sí & Sí & Sí & Sí & Sí \\
\hline Observaciones & 4.462 & 3.842 & 3.558 & 3.339 & 3.359 \\
\hline R-cuadrado & 0,107 & 0,126 & 0,095 & 0,079 & 0,114 \\
\hline
\end{tabular}

Nota: Errores estándar robustos entre paréntesis. ${ }^{* * *} \mathrm{p}<0,01,{ }^{* *} \mathrm{p}<0,05,{ }^{*} \mathrm{p}<0,1$. Resultados ajustados por factor de expansión.

Fuente: ENEMDU - Diciembre 2003-2014. 
Tabla A.8: Modelo de bienestar global por quintiles de ingreso.

\begin{tabular}{|c|c|c|c|c|c|}
\hline VARIABLES & (1) & $(2)$ & $(3)$ & $(4)$ & $(5)$ \\
\hline Logaritmo ingreso & $\begin{array}{l}0,0334 \\
(0,0837)\end{array}$ & $\begin{array}{l}0,0646 \\
(0,111)\end{array}$ & $\begin{array}{l}0,0536 \\
(0,100)\end{array}$ & $\begin{array}{l}-0,000758 \\
(0,107)\end{array}$ & $\begin{array}{l}0,104 \\
(0,101)\end{array}$ \\
\hline Considera_pobre & $\begin{array}{l}-0,0922 \\
(0,143)\end{array}$ & $-0,288^{*}$ & $\begin{array}{l}0,0552 \\
(0,126)\end{array}$ & $\begin{array}{l}0,166 \\
(0,115)\end{array}$ & $\begin{array}{l}0,0418 \\
(0,121)\end{array}$ \\
\hline $\begin{array}{l}\text { Considera_pobre } \\
\text { (relativo) }\end{array}$ & $\begin{array}{l}-0,132^{* * *} \\
(0,0330)\end{array}$ & $\begin{array}{l}-0,127^{* * *} \\
(0,0366)\end{array}$ & $\begin{array}{l}-0,168^{* * *} \\
(0,0360)\end{array}$ & $\begin{array}{l}-0,201^{* * *} \\
(0,0355)\end{array}$ & $\begin{array}{l}-0,202^{* * *} \\
(0,0358)\end{array}$ \\
\hline $\begin{array}{l}\text { Logaritmo } \\
\text { aspiraciones }\end{array}$ & $\begin{array}{l}-0,436^{* * *} \\
(0,0956)\end{array}$ & $\begin{array}{l}-0,350^{* * *} \\
(0,113)\end{array}$ & $\begin{array}{l}-0,268^{* * *} \\
(0,0976)\end{array}$ & $\begin{array}{l}0,0348 \\
(0,0995)\end{array}$ & $\begin{array}{l}-0,0553 \\
(0,0843)\end{array}$ \\
\hline \multicolumn{6}{|c|}{$\begin{array}{l}\text { Condición de actividad } \\
\text { (Ref: Adecuado) }\end{array}$} \\
\hline $\begin{array}{l}\text { Inadecuado/ } \\
\text { Desempleado }\end{array}$ & $\begin{array}{r}-0,0190 \\
(0,150)\end{array}$ & $\begin{array}{l}-0,228 \\
(0,142)\end{array}$ & $\begin{array}{l}-0,208 \\
(0,132)\end{array}$ & $\begin{array}{l}-0,396^{* * *} \\
(0,124)\end{array}$ & $\begin{array}{l}0,220 \\
(0,135)\end{array}$ \\
\hline Inactivo & $\begin{array}{l}-0,242 \\
(0,234)\end{array}$ & $\begin{array}{l}0,158 \\
(0,223)\end{array}$ & $\begin{array}{l}-0,156 \\
(0,223)\end{array}$ & $\begin{array}{l}-0,588^{* *} \\
(0,236)\end{array}$ & $\begin{array}{l}0,337^{*} \\
(0,201)\end{array}$ \\
\hline \multicolumn{6}{|c|}{$\begin{array}{l}\text { Nivel de instrucción } \\
\text { (Ref: Ninguna) }\end{array}$} \\
\hline Primaria & $\begin{array}{l}0,362 \\
(0,229)\end{array}$ & $\begin{array}{l}0,0187 \\
(0,330)\end{array}$ & $\begin{array}{l}-0,192 \\
(0,314)\end{array}$ & $\begin{array}{l}-0,367 \\
(0,288)\end{array}$ & $\begin{array}{l}-0,358 \\
(0,358)\end{array}$ \\
\hline Secundaria & $\begin{array}{l}0,586^{* *} \\
(0,295)\end{array}$ & $\begin{array}{l}0,0424 \\
(0,391)\end{array}$ & $\begin{array}{l}0,0119 \\
(0,372)\end{array}$ & $\begin{array}{l}-0,259 \\
(0,367)\end{array}$ & $\begin{array}{l}-0,279 \\
(0,443)\end{array}$ \\
\hline Superior & $\begin{array}{l}0,819 \\
(0,682)\end{array}$ & $\begin{array}{l}0,137 \\
(0,567)\end{array}$ & $\begin{array}{l}0,239 \\
(0,522)\end{array}$ & $\begin{array}{l}-0,478 \\
(0,477)\end{array}$ & $\begin{array}{l}0,0948 \\
(0,540)\end{array}$ \\
\hline \multicolumn{6}{|l|}{$\begin{array}{ll}\text { Estado civil } & \text { (Ref: } \\
\text { Casado/Unido) } & \end{array}$} \\
\hline Soltero/Solo & $\begin{array}{l}0,0305 \\
(0,232)\end{array}$ & $\begin{array}{l}0,00558 \\
(0,300)\end{array}$ & $\begin{array}{l}0,387 \\
(0,242)\end{array}$ & $\begin{array}{l}-0,221 \\
(0,227)\end{array}$ & $\begin{array}{l}-0,282 \\
(0,237)\end{array}$ \\
\hline Edad & $\begin{array}{l}-0,120 \\
(0,0994)\end{array}$ & $\begin{array}{l}-0,116 \\
(0,124)\end{array}$ & $\begin{array}{l}0,103 \\
(0,140)\end{array}$ & $\begin{array}{l}0,0675 \\
(0,152)\end{array}$ & $\begin{array}{l}-0,0738 \\
(0,120)\end{array}$ \\
\hline Edad $^{2}$ & $\begin{array}{l}0,000804 \\
(0,000826)\end{array}$ & $\begin{array}{l}0,000557 \\
(0,00102)\end{array}$ & $\begin{array}{l}-0,000728 \\
(0,00115)\end{array}$ & $\begin{array}{l}-0,000934 \\
(0,00112)\end{array}$ & $\begin{array}{l}0,000812 \\
(0,00105)\end{array}$ \\
\hline Tamaño del hogar & $\begin{array}{l}-0,0443 \\
(0,0478)\end{array}$ & $\begin{array}{l}-0,00428 \\
(0,0559)\end{array}$ & $\begin{array}{l}0,0178 \\
(0,0470)\end{array}$ & $\begin{array}{l}0,0673 \\
(0,0462)\end{array}$ & $\begin{array}{l}0,00377 \\
(0,0549)\end{array}$ \\
\hline Práctica de deporte & $\begin{array}{l}0,0471 \\
(0,142)\end{array}$ & $\begin{array}{l}0,148 \\
(0,147)\end{array}$ & $\begin{array}{l}-0,130 \\
(0,122)\end{array}$ & $\begin{array}{l}0,158 \\
(0,111)\end{array}$ & $\begin{array}{l}0,110 \\
(0,113)\end{array}$ \\
\hline Año 2014 & $\begin{array}{l}-0,0514 \\
(0,0720)\end{array}$ & $\begin{array}{l}-0,136^{*} \\
(0,0781)\end{array}$ & $\begin{array}{l}-0,207^{* * *} \\
(0,0760)\end{array}$ & $\begin{array}{l}-0,232^{* * *} \\
(0,0809)\end{array}$ & $\begin{array}{l}-0,262^{* * *} \\
(0,0735)\end{array}$ \\
\hline Constante & $\begin{array}{l}13,87^{* * *} \\
(2,929)\end{array}$ & $\begin{array}{l}14,33^{* * *} \\
(3,771)\end{array}$ & $\begin{array}{l}6,468 \\
(4,301)\end{array}$ & $\begin{array}{l}8,206^{*} \\
(4,778)\end{array}$ & $\begin{array}{l}10,24^{* * *} \\
(3,479)\end{array}$ \\
\hline Efectos fijos & Sí & Sí & Sí & Sí & Sí \\
\hline Observaciones & 4.468 & 3.841 & 3.558 & 3.342 & 3.360 \\
\hline R-cuadrado & 0,034 & 0,047 & 0,043 & 0,064 & 0,062 \\
\hline
\end{tabular}

Nota: Errores estándar robustos entre paréntesis. ${ }^{* * *} \mathrm{p}<0,01,{ }^{* *} \mathrm{p}<0,05,{ }^{*} \mathrm{p}<0,1$. Resultados ajustados por factor de expansión.

Fuente: ENEMDU - Diciembre 2003-2014. 
Tabla A.9: Modelos para las dimensiones de bienestar.

\begin{tabular}{|c|c|c|c|c|c|c|c|}
\hline VARIABLES & $\begin{array}{l}\text { Profesión } \\
\qquad(1)\end{array}$ & $\begin{array}{c}\text { Trabajo } \\
(2)\end{array}$ & $\begin{array}{c}\text { Situación } \\
\text { financiera } \\
(3)\end{array}$ & $\begin{array}{c}\text { Estado } \\
\text { de salud } \\
(4)\end{array}$ & $\begin{array}{c}\text { Vivienda } \\
(5)\end{array}$ & $\begin{array}{c}\text { Tiempo } \\
\text { libre } \\
(6)\end{array}$ & $\begin{array}{c}\text { Familia } \\
\text { (7) }\end{array}$ \\
\hline Logaritmo ingreso & $\begin{array}{l}0,223^{* * *} \\
(0,0834)\end{array}$ & $\begin{array}{l}0,254^{* * *} \\
(0,0750)\end{array}$ & $\begin{array}{l}0,203^{* * *} \\
(0,0603)\end{array}$ & $\begin{array}{l}0,130^{* *} \\
(0,0610)\end{array}$ & $\begin{array}{l}0,0625 \\
(0,0634)\end{array}$ & $\begin{array}{l}0,0525 \\
(0,0689)\end{array}$ & $\begin{array}{l}0,0397 \\
(0,0521)\end{array}$ \\
\hline $\begin{array}{l}\text { Considera_pobre } \\
\text { (absoluto) }\end{array}$ & $\begin{array}{l}-0,114 \\
(0,105)\end{array}$ & $\begin{array}{c}-0,194^{* *} \\
(0,0941)\end{array}$ & $\begin{array}{l}-0,248 * * * \\
(0,0793)\end{array}$ & $\begin{array}{l}-0,118 \\
(0,0752)\end{array}$ & $\begin{array}{l}-0,0658 \\
(0,0808)\end{array}$ & $\begin{array}{l}-0,111 \\
(0,0777)\end{array}$ & $\begin{array}{l}-0,126^{*} \\
(0,0675)\end{array}$ \\
\hline $\begin{array}{l}\text { Considera_pobre } \\
\text { (relativo) }\end{array}$ & & $\begin{array}{l}-0,155^{* * *} \\
(0,0281)\end{array}$ & $\begin{array}{l}-0,327^{* * *} \\
(0,0219)\end{array}$ & $\begin{array}{l}-0,176^{* * *} \\
(0,0219)\end{array}$ & $\begin{array}{l}-0,225^{* * *} \\
(0,0238)\end{array}$ & $\begin{array}{l}-0,170^{* * *} \\
(0,0234)\end{array}$ & $\begin{array}{l}-0,0704^{* * *} \\
(0,0200)\end{array}$ \\
\hline $\begin{array}{l}\text { Logaritmo } \\
\text { aspiraciones }\end{array}$ & $\begin{array}{l}-0,0391 \\
(0,0839)\end{array}$ & $\begin{array}{l}-0,114 \\
(0,0721)\end{array}$ & $\begin{array}{l}0,0382 \\
(0,0617)\end{array}$ & $\begin{array}{l}-0,0960 \\
(0,0595)\end{array}$ & $\begin{array}{l}-0,120^{* *} \\
(0,0610)\end{array}$ & $\begin{array}{l}-0,214^{* * *} \\
(0,0606)\end{array}$ & $\begin{array}{l}-0,233^{* * *} \\
(0,0511)\end{array}$ \\
\hline R-cuadrado & 0,033 & 0,038 & 0,101 & 0,052 & 0,045 & 0,044 & 0,024 \\
\hline Número de hogares & 8.387 & 8.439 & 9.111 & 9.111 & 9.111 & 9.111 & 9.112 \\
\hline VARIABLES & $\begin{array}{c}\text { Educación } \\
(8) \\
\end{array}$ & $\begin{array}{c}\text { Medio } \\
\text { ambiente } \\
(9) \\
\end{array}$ & $\begin{array}{c}\text { Vida social } \\
(10) \\
\end{array}$ & $\begin{array}{l}\text { Estado } \\
\text { civil } \\
(11) \\
\end{array}$ & $\begin{array}{l}\text { Participación } \\
\text { comunidad } \\
(12)\end{array}$ & $\begin{array}{c}\text { Gobierno } \\
(13) \\
\end{array}$ & $\begin{array}{c}\text { Bienestar } \\
\text { global } \\
(14)\end{array}$ \\
\hline Logaritmo ingreso & $\begin{array}{l}-0,00451 \\
(0,0666)\end{array}$ & $\begin{array}{l}0,0553 \\
(0,0615)\end{array}$ & $\begin{array}{l}0,0579 \\
(0,0600)\end{array}$ & $\begin{array}{c}-0,00972 \\
(0,0646)\end{array}$ & $\begin{array}{l}-0,000248 \\
(0,0620)\end{array}$ & $\begin{array}{l}0,0372 \\
(0,0698)\end{array}$ & $\begin{array}{l}0,0335 \\
(0,0493)\end{array}$ \\
\hline $\begin{array}{l}\text { Considera_pobre } \\
\text { (absoluto) }\end{array}$ & $\begin{array}{l}-0,163^{* *} \\
(0,0818)\end{array}$ & $\begin{array}{c}-0,0589 \\
(0,0724)\end{array}$ & $\begin{array}{l}-0,0954 \\
(0,0716)\end{array}$ & $\begin{array}{l}-0,100 \\
(0.0827)\end{array}$ & $\begin{array}{c}-0,0194 \\
(0.0748)\end{array}$ & $\begin{array}{l}-0,0493 \\
(0,0836)\end{array}$ & $\begin{array}{l}-0,0394 \\
(0,0629)\end{array}$ \\
\hline $\begin{array}{l}\text { Considera_pobre } \\
\text { (relativo) }\end{array}$ & $\begin{array}{l}-0,202^{* * *} \\
(0,0246)\end{array}$ & $\begin{array}{l}-0,106 * * * \\
(0,0223)\end{array}$ & $\begin{array}{l}-0,142^{* * *} \\
(0,0216)\end{array}$ & $\begin{array}{l}-0,101^{* * *} \\
(0,0234)\end{array}$ & $\begin{array}{l}-0,154^{* * *} \\
(0,0237)\end{array}$ & $\begin{array}{l}-0,125^{* * *} \\
(0,0253)\end{array}$ & $\begin{array}{l}-0,127 * * * \\
(0,0178)\end{array}$ \\
\hline $\begin{array}{l}\text { Logaritmo } \\
\text { aspiraciones }\end{array}$ & $\begin{array}{l}-0,176^{* * *} \\
(0,0644)\end{array}$ & $\begin{array}{l}-0,0745 \\
(0,0601)\end{array}$ & $\begin{array}{l}-0,257^{* * *} \\
(0,0555)\end{array}$ & $\begin{array}{l}-0,0982 \\
(0,0610)\end{array}$ & $\begin{array}{l}-0,296^{* * *} \\
(0,0637)\end{array}$ & $\begin{array}{l}-0,111^{*} \\
(0,0634)\end{array}$ & $\begin{array}{l}-0,234^{* * *} \\
(0,0498)\end{array}$ \\
\hline R-cuadrado & 0,038 & 0,030 & 0,034 & 0,026 & 0,038 & 0,143 & 0,051 \\
\hline Número de hogares & 9.112 & 9.111 & 9.111 & 9.111 & 9.112 & 9.11 & 9.111 \\
\hline
\end{tabular}




\section{A.4. Pruebas de robustez}

Tabla A.10: Bienestar financiero e ingreso laboral del jefe de hogar.

\begin{tabular}{|c|c|c|c|c|c|c|c|c|c|}
\hline VARIABLES & $(1)$ & $(2)$ & $(3)$ & $(4)$ & $(5)$ & (6) & $(7)$ & $(8)$ & (9) \\
\hline Ingreso & $0,702^{* * *}$ & & & & $0,312^{* * *}$ & $0,321 * * *$ & $0,215^{* * *}$ & $0,180^{* * *}$ & $0,167 * *$ \\
\hline laboral & $(0,0234)$ & & & & $(0,0251)$ & $(0,0257)$ & $(0,0475)$ & $(0,0549)$ & $(0,0654)$ \\
\hline Considera_pobre & & $-1,513^{* * *}$ & & & $-0,419^{* * *}$ & $-0,431 * * *$ & $-0,246 * * *$ & $-0,244^{* * *}$ & $-0,237 * * *$ \\
\hline (absoluto) & & $(0,0412)$ & & & $(0,0520)$ & $(0,0526)$ & $(0,0800)$ & $(0,0801)$ & $(0,0896)$ \\
\hline Considera_pobre & & & $-0,535^{* * *}$ & & $-0,386^{* * *}$ & $-0,388 * * *$ & $-0,357 * * *$ & $-0,357 * * *$ & $-0,348^{* * *}$ \\
\hline (relativo) & & & $(0,0113)$ & & $(0,0156)$ & $(0,0158)$ & $(0,0226)$ & $(0,0225)$ & $(0,0256)$ \\
\hline Logaritmo & & & & $0,603^{* * *}$ & $0,0916^{* * *}$ & $0,0927 * * *$ & $-0,00860$ & $-0,00632$ & 0,0486 \\
\hline aspiraciones & & & & $(0,0276)$ & $(0,0280)$ & $(0,0288)$ & $(0,0568)$ & $(0,0603)$ & $(0,0682)$ \\
\hline Mujer & & & & & & $\begin{array}{l}0,0584 \\
(0,0493)\end{array}$ & & & \\
\hline Minoría & & & & & & $-0,0669$ & & & \\
\hline étnica & & & & & & $(0,0562)$ & & & \\
\hline $\begin{array}{l}\text { Condición de ac- } \\
\text { tividad (Ref: Ade- } \\
\text { cuado) }\end{array}$ & & & & & & & & & \\
\hline $\begin{array}{l}\text { Inadecuado/ } \\
\text { Desempleado }\end{array}$ & & & & & & & & $\begin{array}{l}-0,114 \\
(0,0911)\end{array}$ & $\begin{array}{l}-0,134 \\
(0,102)\end{array}$ \\
\hline $\begin{array}{l}\text { Nivel de instrucción } \\
\text { (Ref: Ninguna) }\end{array}$ & & & & & & & & & \\
\hline Primaria & & & & & & & & $\begin{array}{c}-0,0680 \\
(0,198)\end{array}$ & $\begin{array}{l}-0,348 \\
(0,269)\end{array}$ \\
\hline Secundaria & & & & & & & & $\begin{array}{l}-0,107 \\
(0,236)\end{array}$ & $\begin{array}{l}-0,356 \\
(0,306)\end{array}$ \\
\hline Superior & & & & & & & & $\begin{array}{c}-0,0115 \\
(0,319)\end{array}$ & $\begin{array}{l}-0,227 \\
(0,379)\end{array}$ \\
\hline \multicolumn{10}{|l|}{$\begin{array}{l}\text { Estado civil (Ref: } \\
\text { Casado/Unido) }\end{array}$} \\
\hline Soltero/Solo & & & & & & & & $\begin{array}{l}0,235 \\
(0,158)\end{array}$ & $\begin{array}{l}0,180 \\
(0,182)\end{array}$ \\
\hline Edad & & & & & & & & $\begin{array}{l}0,0244 \\
(0,0886)\end{array}$ & $\begin{array}{l}0,0880 \\
(0,113)\end{array}$ \\
\hline Edad $^{2}$ & & & & & & & & $\begin{array}{l}-0,000112 \\
(0,000869)\end{array}$ & $\begin{array}{l}-0,000601 \\
(0,00116)\end{array}$ \\
\hline \multicolumn{10}{|l|}{$\begin{array}{l}\text { Percepción democra- } \\
\text { cia (Ref: Muy de } \\
\text { acuerdo) }\end{array}$} \\
\hline Poco de acuerdo & & & & & & & & & $\begin{array}{l}0,0167 \\
(0,0742)\end{array}$ \\
\hline En desacuerdo & & & & & & & & & $\begin{array}{l}0,0269 \\
(0,0889)\end{array}$ \\
\hline Seguridad & & & & & & & & & $\begin{array}{l}0,240 * * * \\
(0,0485)\end{array}$ \\
\hline Confianza & & & & & & & & & $\begin{array}{l}0,104 * * * \\
(0,0375)\end{array}$ \\
\hline Tamaño del hogar & & & & & & & & $\begin{array}{l}0,0132 \\
(0,0334)\end{array}$ & $\begin{array}{l}0,0410 \\
(0,0392)\end{array}$ \\
\hline Práctica de deporte & & & & & & & & $\begin{array}{l}0,0225 \\
(0,0710)\end{array}$ & $\begin{array}{l}0,0337 \\
(0,0770)\end{array}$ \\
\hline Año 2014 & $\begin{array}{l}-0,157^{* * *} \\
(0,0409)\end{array}$ & $\begin{array}{l}-0,193^{* * *} \\
(0,0397)\end{array}$ & $\begin{array}{l}-0,0942^{* *} \\
(0,0377)\end{array}$ & $\begin{array}{l}-0,189 * * * \\
(0,0414)\end{array}$ & $\begin{array}{l}-0,132^{* * *} \\
(0,0378)\end{array}$ & $\begin{array}{l}-0,132^{* * *} \\
(0,0377)\end{array}$ & $\begin{array}{l}-0,121^{* * *} \\
(0,0386)\end{array}$ & $\begin{array}{l}-0,142^{* * *} \\
(0,0447)\end{array}$ & $\begin{array}{l}-0,172^{* * *} \\
(0,0501)\end{array}$ \\
\hline Constante & $\begin{array}{l}1,887^{* * *} \\
(0,136)\end{array}$ & $\begin{array}{l}6,872^{* * *} \\
(0,0381)\end{array}$ & $\begin{array}{l}8,871 * * * \\
(0,0676)\end{array}$ & $\begin{array}{l}2,726^{* * *} \\
(0,144)\end{array}$ & $\begin{array}{l}6,076^{* * *} \\
(0,212)\end{array}$ & $\begin{array}{l}6,100^{* * *} \\
(0,228)\end{array}$ & $\begin{array}{l}6,871 * * * \\
(0,405)\end{array}$ & $\begin{array}{l}6,166^{* * *} \\
-2,295\end{array}$ & $\begin{array}{l}3,113 \\
-2,770\end{array}$ \\
\hline Dummies provincia & No & No & No & No & No & Sí & No & No & No \\
\hline Efectos fijos & No & No & No & No & No & No & Sí & Sí & Sí \\
\hline Observaciones & 14.59 & 15.297 & 15.295 & 15.29 & 14.581 & 14.581 & 14.581 & 14.55 & 12.831 \\
\hline R-cuadrado & 0,097 & 0,125 & 0,201 & 0,049 & 0,231 & 0,236 & 0,091 & 0,093 & 0,108 \\
\hline
\end{tabular}

Nota: Errores estándar robustos entre paréntesis. ${ }^{* * *} \mathrm{p}<0,01,{ }^{* *} \mathrm{p}<0,05,{ }^{*} \mathrm{p}<0,1$. Resultados ajustados por factor de expansión.

Fuente: ENEMDU - Diciembre 2003-2014. 
Tabla A.11: Bienestar global e ingreso laboral del jefe de hogar.

\begin{tabular}{|c|c|c|c|c|c|c|c|c|c|}
\hline VARIABLES & $(1)$ & $(2)$ & (3) & $(4)$ & $(5)$ & $(6)$ & (7) & (8) & (9) \\
\hline Ingreso & $0,276 * * *$ & & & & $0,155^{* * *}$ & $0,135^{* * *}$ & 0,0622 & 0,0342 & 0,00880 \\
\hline laboral & $(0,0175)$ & & & & $(0,0199)$ & $(0,0206)$ & $(0,0382)$ & $(0,0433)$ & $(0,0495)$ \\
\hline Considera_pobre & & $-0,565^{* * *}$ & & & $-0,144^{* * *}$ & $-0,168 * * *$ & $-0,0102$ & $-0,00554$ & $-0,00671$ \\
\hline (absoluto) & & $(0,0309)$ & & & $(0,0417)$ & $(0,0422)$ & $(0,0673)$ & $(0,0675)$ & $(0,0724)$ \\
\hline Considera_pobre & & & $-0,209^{* * *}$ & & $-0,161^{* * *}$ & $-0,170^{* * *}$ & $-0,160 * * *$ & $-0,158 * * *$ & $-0,141^{* * *}$ \\
\hline (relativo) & & & $(0,00893)$ & & $(0,0120)$ & $(0,0121)$ & $(0,0187)$ & $(0,0187)$ & $(0,0204)$ \\
\hline Logaritmo & & & & $0,141^{* * *}$ & $-0,0762^{* * *}$ & $-0,0733^{* * *}$ & $-0,232 * * *$ & $-0,232^{* * *}$ & $-0,246^{* * *}$ \\
\hline aspiraciones & & & & $(0,0205)$ & $(0,0230)$ & $(0,0236)$ & $(0,0503)$ & $(0,0518)$ & $(0,0578)$ \\
\hline Mujer & & & & & & $\begin{array}{l}-0,0901^{* *} \\
(0,0393)\end{array}$ & & & \\
\hline Minoría & & & & & & 0,0396 & & & \\
\hline étnica & & & & & & $(0,0454)$ & & & \\
\hline $\begin{array}{l}\text { Condición de ac- } \\
\text { tividad (Ref: Ade- } \\
\text { cuado) }\end{array}$ & & & & & & & & & \\
\hline Inadecuado/ & & & & & & & & $-0,100$ & $-0,109$ \\
\hline Desempleado & & & & & & & & $(0,0729)$ & $(0.0792)$ \\
\hline \multicolumn{10}{|l|}{$\begin{array}{l}\text { Nivel de instrucción } \\
\text { (Ref: Ninguna) }\end{array}$} \\
\hline Primaria & & & & & & & & $\begin{array}{l}-0,228 \\
(0,191)\end{array}$ & $\begin{array}{l}-0,463^{*} \\
(0,249)\end{array}$ \\
\hline \multirow[t]{2}{*}{ Secundaria } & & & & & & & & $-0,0508$ & $-0,339$ \\
\hline & & & & & & & & $(0,221)$ & $(0,278)$ \\
\hline \multirow[t]{2}{*}{ Superior } & & & & & & & & 0,116 & $-0,172$ \\
\hline & & & & & & & & $(0,292)$ & $(0,340)$ \\
\hline \multirow{2}{*}{\multicolumn{10}{|c|}{$\begin{array}{l}\text { Estado civil (Ref: } \\
\text { Casado/Unido) }\end{array}$}} \\
\hline & & & & & & & & & \\
\hline \multirow[t]{2}{*}{ Soltero/Solo } & & & & & & & & 0,00345 & $-0,0304$ \\
\hline & & & & & & & & $(0,150)$ & $(0,162)$ \\
\hline Edad & & & & & & & & $-0,0189$ & 0,0397 \\
\hline & & & & & & & & $(0,0790)$ & $(0,0888)$ \\
\hline Edad $^{2}$ & & & & & & & & $2,13 \mathrm{e}-06$ & $-0,000617$ \\
\hline & & & & & & & & $(0,000725)$ & $(0,000858)$ \\
\hline \multicolumn{10}{|l|}{$\begin{array}{l}\text { Percepción democra- } \\
\text { cia (Ref: Muy de } \\
\text { acuerdo) }\end{array}$} \\
\hline \multirow[t]{2}{*}{ Poco de acuerdo } & & & & & & & & & 0,0211 \\
\hline & & & & & & & & & $(0,0616)$ \\
\hline \multirow[t]{2}{*}{ En desacuerdo } & & & & & & & & & 0,0786 \\
\hline & & & & & & & & & $(0,0728)$ \\
\hline Seguridad & & & & & & & & & $\begin{array}{l}0,0576 \\
(0,0395)\end{array}$ \\
\hline \multirow[t]{2}{*}{ Confianza } & & & & & & & & & $0,198^{* * *}$ \\
\hline & & & & & & & & & $(0,0321)$ \\
\hline \multirow[t]{2}{*}{ Tamaño del hogar } & & & & & & & & 0,0129 & 0,0131 \\
\hline & & & & & & & & $(0,0290)$ & $(0,0331)$ \\
\hline \multirow[t]{2}{*}{ Práctica de deporte } & & & & & & & & 0,0854 & 0,0422 \\
\hline & & & & & & & & $(0,0643)$ & $(0,0684)$ \\
\hline \multirow[t]{2}{*}{ Año 2014} & $-0,194^{* * *}$ & $-0,205^{* * *}$ & $-0,168^{* * *}$ & $-0,197 * * *$ & $-0,176^{* * *}$ & $-0,174 * * *$ & $-0,157 * * *$ & $-0,142^{* * *}$ & $-0,134^{* * *}$ \\
\hline & $(0,0309)$ & $(0,0302)$ & $(0,0298)$ & $(0,0306)$ & $(0,0304)$ & $(0,0302)$ & $(0,0324)$ & $(0,0384)$ & $(0,0426)$ \\
\hline \multirow[t]{2}{*}{ Constante } & $6,150^{* * *}$ & $8,094^{* * *}$ & $8,892^{* * *}$ & $6,983^{* * *}$ & $8,239^{* * *}$ & $8,264^{* * *}$ & $9,475^{* * *}$ & $10,61^{* * *}$ & $8,846^{* * *}$ \\
\hline & $(0,103)$ & $(0,0289)$ & $(0,0523)$ & $(0,108)$ & $(0,168)$ & $(0,181)$ & $(0,319)$ & $-2,136$ & $-2,327$ \\
\hline Dummies provincia & No & No & No & No & No & Sí & No & No & No \\
\hline Efectos fijos & No & No & No & No & No & No & Sí & Sí & Sí \\
\hline Observaciones & 14.596 & 15.304 & 15.302 & 15.297 & 14.587 & 14.587 & 14.587 & 14.556 & 12.836 \\
\hline R-cuadrado & 0,030 & 0,035 & 0,058 & 0,008 & 0,066 & 0,077 & 0,033 & 0,036 & 0,052 \\
\hline
\end{tabular}

Nota: Errores estándar robustos entre paréntesis. ${ }^{* * *} \mathrm{p}<0,01,{ }^{* *} \mathrm{p}<0,05,{ }^{*} \mathrm{p}<0,1$. Resultados ajustados por factor de expansión.

Fuente: ENEMDU - Diciembre 2003-2014. 
Tabla A.12: Especificación del bienestar financiero y global como variables binarias.

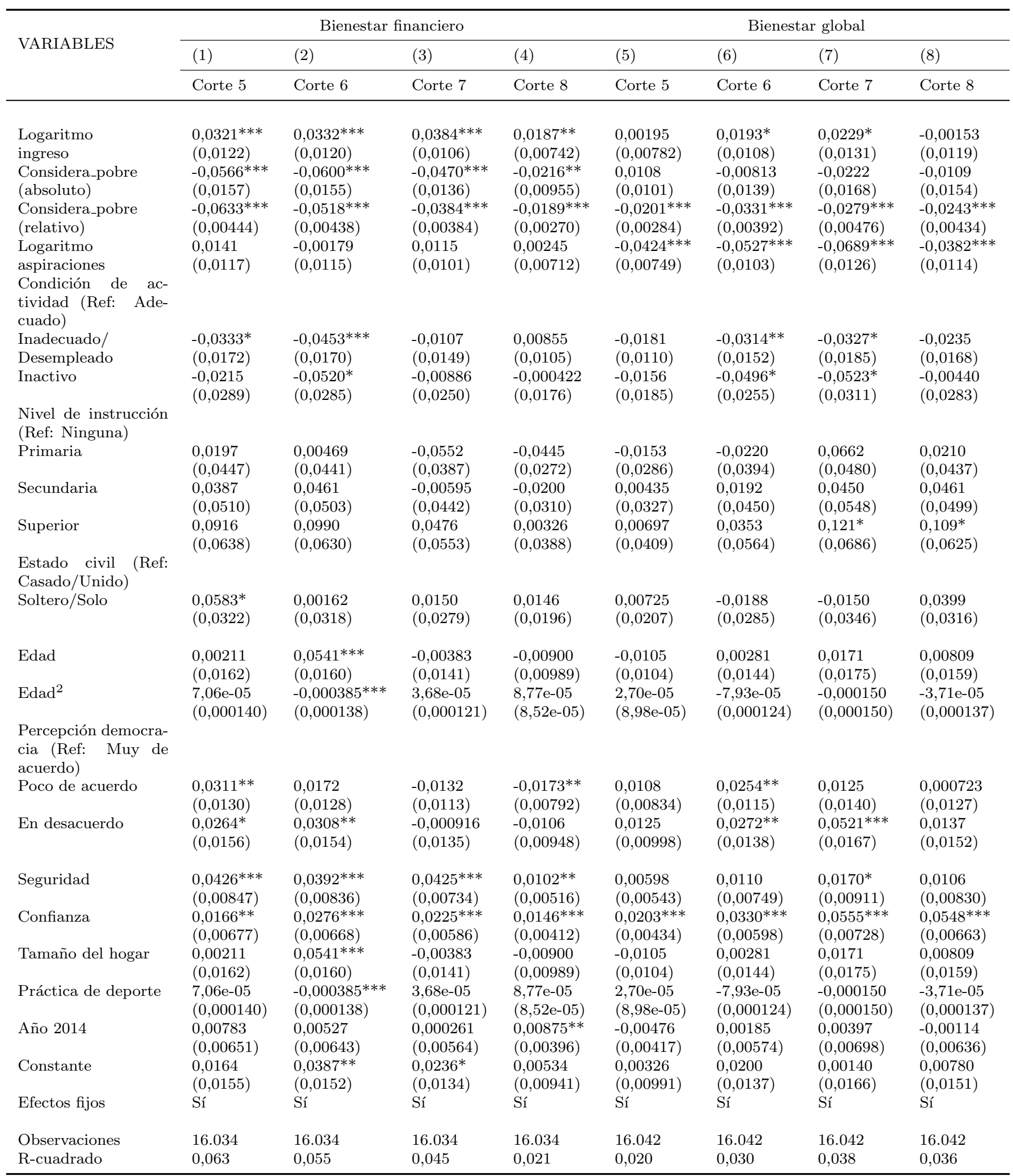

Nota: Errores estándar robustos entre paréntesis. ${ }^{* * *} \mathrm{p}<0,01,{ }^{* *} \mathrm{p}<0,05,{ }^{*} \mathrm{p}<0,1$. Resultados ajustados por factor de expansión.

La variable dependiente es una variable binaria que distingue a quienes poseen un nivel de bienestar inferior o igual al valor de corte con el resto.

Fuente: ENEMDU - Diciembre 2003-2014. 